
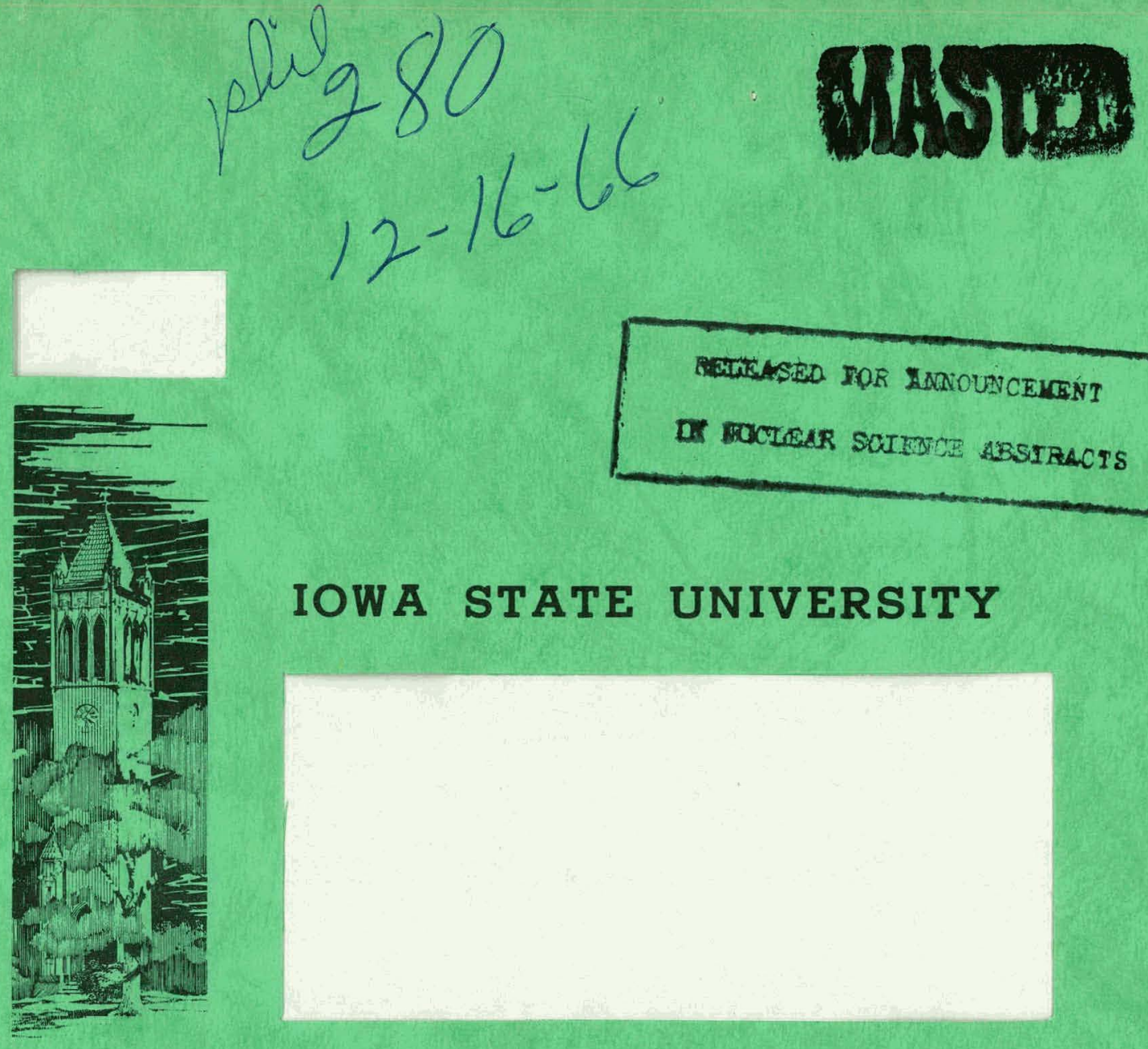

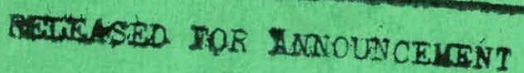 \\ D. BUCLEAR SCIHUCE ABSTRAC'S
}

IOWA STATE UNIVERSITY

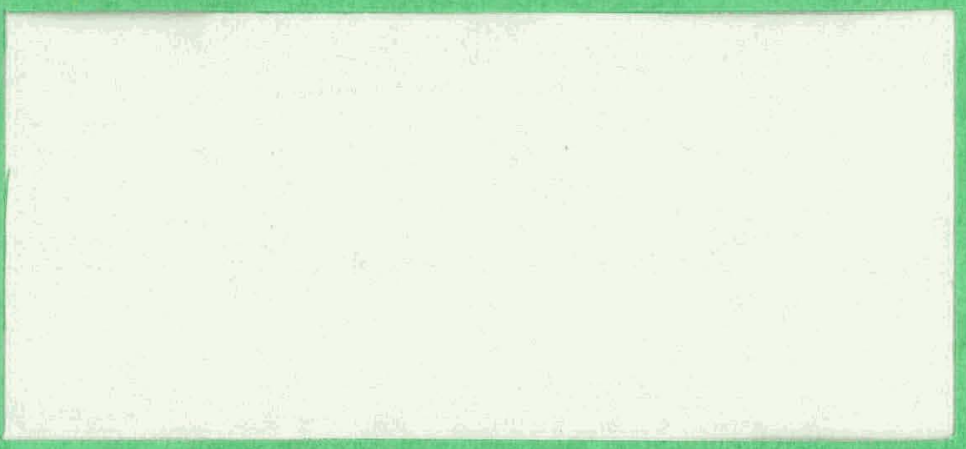

AMIES LADORATORY

\begin{tabular}{l} 
RESEARCH AND \\
\hline DEVELOPMENT \\
\hline REPORT
\end{tabular}

U.S.A.E.C.

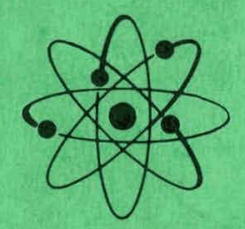




\section{DISCLAIMER}

This report was prepared as an account of work sponsored by an agency of the United States Government. Neither the United States Government nor any agency Thereof, nor any of their employees, makes any warranty, express or implied, or assumes any legal liability or responsibility for the accuracy, completeness, or usefulness of any information, apparatus, product, or process disclosed, or represents that its use would not infringe privately owned rights. Reference herein to any specific commercial product, process, or service by trade name, trademark, manufacturer, or otherwise does not necessarily constitute or imply its endorsement, recommendation, or favoring by the United States Government or any agency thereof. The views and opinions of authors expressed herein do not necessarily state or reflect those of the United States Government or any agency thereof. 


\section{DISCLAIMER}

Portions of this document may be illegible in electronic image products. Images are produced from the best available original document. 


\section{r. $300:=65$}

\section{UNITED STATES ATOMIC ENERGY COMMISSION}

Research and Development Report

\section{MEASUR EMENT OF THE THERMAL NEUTRON SPECTRUM FROM A NEUTRON CHOPPER}

by

Gary A. Sleege and Roger C. Camp

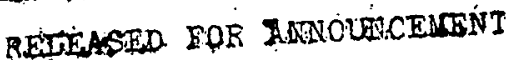

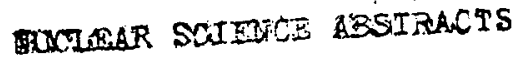

\section{LEGAL NOTICE}

A States, nor the Commission, nor any person acting on behalf of the Commission

A. Makes any warranty or representation, expressed or implied, with respect to the accuracy, completeness, or usefulness of the information contained in this report, or that the use of any informatson, apparatus, method, or proness disclosed in this report may not infringe privately ouned righta; or

B. Assumes any liabllitles with respect to the use of, or for damages resulting from the use of any fnformation, apparatus, method, or process disclosed in thlo report.

As used in the above, "person acting on behalf of the Commisaion" includes any employer contractor. to the extent that ployecor contractor prepares. dis disseminates, or provides access

L.........

September, 1966

Ampes Laboratory

at

Iowa State University of Science and Technology

$F$. H. Spedding, Director

Contract W-7405 eng -82 
- This report is distributed according to the category Reactor Technology (UC-80) as listed in TID-4500, September 1, 1966.

\section{LEGAL NOTICE}

This report was prcparcd as an account of Government sponsorcd work. Neither the United States, nor the Commission, nor any person acting on behalf of the Commission:

A. Makes any warranty or representation, expressed or implied, with respect to the accuracy, completeness, or usefulness of the information contained in this report, or that the use of any information, apparatus, method, or process disclosed in this report may not infringe privately owned rights; or

B. Assumes any liabilities with respect to the use of, or for damages resulting from the use of any information, apparatus, method, or process disclosed in this report.

As used in the above, "person acting on behalf of the Commission" includes any employee or contractor of the Commission, or employee of such contrartin, th the extent. that. surh emplnyee nr rontrartar if the Eommission; or employee of such contractor prcpares, disseminates, or provides access to, any information pursuant to his employment or contract with the Commission, or his employment with such contractor.

Printed in USA. Prire \$3.00. Available from the Clearinghousc for Federal Scientific àn Technical Information, National

Bureau of Standards, U. S. Department of

Commerce, Springfield, Virginia 
ABSTRACT

1. INTRODUCTION

11. REVIEW OF LITERATURE 2

III. SYSTEM DESCRIPTION 6

A. Method 6

B. Desired Accuracy 9

C. Desired Results 9

IV. SYSTEM DESIGN IO

A. Flight Time Versus Kinetic Energy 10

B. Fundamental Basis $: 11$

$\begin{array}{ll}\text { C. Magnitude of Output Voltage } & 12\end{array}$

D. Kinetic Energy Versus Channel Number . 12

E. Approximation of $\mathrm{K}_{2} / \mathrm{t}^{2}, 13$

F. Error in Output Voltage $\quad 14$

G. Method of Generating the Output Voltage 18

H. Timing Circuit 28

1. Comparator Circuit 30

J. Pulse Gate to Analyzer 32

K. Operation of System 32

V. SYSTEM RESULTS $\quad$. 36

A. Pulse Generator Test 36

B. Neutron Spectrum Measurement 37

VI. DISCUSSION FOR FURTHER STUDY

VII. BIBLIOGRAPHY 
IS -1449 


\title{
MEASUREMENT OF THE THERMAL NEUTRON SPECTRUM FROM A NEUTRON CHOPPER
}

Gary A. Sleege and Roger C. Camp

\begin{abstract}
The electronic system designed in the thesis is a time of flight to energy converter. The flight time over a distance is the information essential to determine the kinetic energy of neutrons. A neutron chopper is used to gate the neutrons so that a starting time is known. A neutron detector is located at the end of the flight path to indicate when the neutron's flight is over. The kinetic energy is then determined by the equation $E=\frac{1}{2} \mathrm{~m} \mathrm{D} / \mathrm{t}^{2}$. A voltage that is proportional to $E$ is generated starting when the neutron chopper opens. This voltage is sampled at the time when a neutron strikes the detector. The voltage pulse produced is proportional to the kinetic energy of the neutron. As neutrons with different kinetic energies strike the detector, a spectrum of voltage amplitudes is produced. These voltage pulses are sent to a pulse height analyzer for storage. The energy range of this system is 0.01 ev to $0.05 \mathrm{ev}$.
\end{abstract}

\footnotetext{
* This report is based on an M.S. thesis submitted by Gary A. Sleege, August, 1966 to Iowa State University, Ames, Iowa.
} 


\section{INTRODUCTION}

Measurement of a neutron kinetic energy spectrum by the time of $f l i g h t$ method usually takes the form of determining the flight time over a known path for many neutrons during a suitable sampling time. At some later time this information is converted into a kinetic energy spectrum. This is the more expedient way to construct the kinetic energy spectrum for high energy neutrons. High energy neutrons have short flight times, which make it necessary to use fast response electronic equipment to measure their flight times. Because of the short time involved, it is difficult to convert flight time into kinetic energy, until later. However, for neutrons in the range of 0.01 electron-volts $(\mathrm{ev})$ to $0.05 \mathrm{ev}$, the $\mathrm{flight}$ time can be converted into kinetic energy with moderately fast response electronic circuits. Thus by changing the flight time to kinetic energy during the sampling time, it will be unnecessary to wait for this conversion at the end of the sampling time. A multichannel analyzer will store this information and then later print the same information on paper tape.

A system to measure neutron kinetic energies by the time of flight method will be designed and built. A kinetic energy spectrum will be taken from thermal column at the Ames Laboratory Research Reactor and will be shown in graphical form. 


\section{I. REVIEW OF LITERATURE}

In 1930, Bothe and Becker (7) first noted the effects of neutrons. The Joliots (7) noticed the effects of neutrons in 1932. Later in 1932, the nature of this particle was identified by James Chadwick (7). Because of its neutral charge, the neutron was discovered much later than charged particles.

Measurement of neutron kinetice energy is more difficult than measuring the kinetic energy of charged particles. Many methods had been devised to detect charged particles and to measure their kinetic energy. Since methods of measurement had already been developed for charged particles, similar methods were tried for neutrons. However, many of the charged particle detectors could not be used. Since neutrons have a neutral charge, their kinetic energy cannot be measured by their curved path in an electric or magnetic field.

Three techniques developed for the measurement of neutron kinetic energy are, by means of photographic emulsions, photomultipller sclntillation counters, and time of flight measurements. In the first of these methods the length of ion trails caused by neutrons colliding with atoms on photographic emulsions are measured to determine the kinetic energy of these neutrons. In the second method, in a similar way, neutrons cause events to occur in scintillation crystals. These crystals give off very weak light bursts, which a photomultiplier detects and changes into a voltage pulse that is proportional to the kinetic energy of the neutron. The third method to measure neutron kinetic energy is to measure their flight time. The kinetic energy of a neutron can be calculated by knowing when it starts 
on a flight through a known distance and when it has completed that flight. As early as 1943, neutron kinetic energies were being measured by the time of flight method by Dr. Fermi (4) at the Argonne National Laboratory. In order to measure the time that it takes a neutron to travel a known distance, a starting signal must be given. A gating system for the neutrons was used so that the starting time of the neutrons would be known. This gate consisted of a revolving cylinder made of a neutron absorbing material with a slit in it to allow neutrons with sufficient velocity to get through this neutron chopper. As the cylinder revolved at 180 revolutions per second, bursts of neutrons with 45 microsecond widths were emitted 360 times a second. A two-sided mirror mounted on the revolving cylinder reflected light to a photoelectric cell to indicate the starting time. A boron-trifloride proportional chamber $\left(\mathrm{BF}_{3}\right)$ was used to detect the neutrons when they had traveled 1.5 meters.

V. Y. A. Averchenkov, a Russian author, tells about a system (1) designed to measure neutrons in the energy range of 2 to 8 Mev by the time of flight method. A 20-channel analyser was used to detect neutrons from $\mathrm{Co}^{60}$ or $\mathrm{Po}^{-} \mathrm{Be}^{-}$. The start signal was obtained by detecting the high velocity gamma ray which accompanies the emission of a neutron.

Another Russian system (2) is described by M. V. Blinov and N. M. Kazarinov. This system is used to measure high energy neutrons by the time of flight method. The start signal was obtained in a similar manner to that of the preceding Russian system. When the fission takes place, a neutron is admitted and the high velocity gamma ray is detected as the start signal. When the stop signal was detected, the system converted the elapsed time to a voltage amplitude which was analyzed by a 
multichannel analyzer. Low voltage amplitudes did not pass through the discriminator. The amplitude of this signal was not proportional to the kinetic energy of the neutrons. The spectrum received from the analyzer was changed to a kinetic energy spectrum by changing the time scale to a non-linear kinetic energy scale. The linearity of the system was within $\pm 2 \%$ over a 100 nsec. of the time range.

Another fast neutron time of flight system (3) is described by Dr. A. T. G. Furguson. This machine measures neutrons in the 1 Mev range. A neutron with the energy of I Mev will travel through the distance of 1 meter in $0.072 \mu \mathrm{sec}$. To measure neutrons in this energy range, a resolution time of 1 nsec. is required. The IBIS (Intense Bunched lon Source) is a Van de Graff machine used to obtain pulsed fast neutrons. The machine actually produces pulses of protons which with focusing techniques give pulses with 1 nsec. duration. The protons then strike a target which contains a material that gives off high energy neutrons of the same duration. An electrode located near the target gives the start signal and a scintillation counter gives the stop signal. To determine the time of flight, the start signal switches on a constant current source onto a capacitor and the stop signal switches it off. The final voltage on the capacitor is directly proportional to the time of flight. This voltage is then analyzed by a pulse height analyzer.

In an article by T. A. Lang, a Chronotron circuit (6) is described which is used to determine the time between two events. It was designed to measure the flight time of neutrons. Two voltage pulses are necessary. The first pulse $(P I)$ indicates the time at which a neutron begins its flight, and the second pulse (P2) indicates the time at which the neutron has 
completed its flight. The circuit used in this case determines the time between these pulses. $P I$ is injected into a circulating pulse amplifier number one (CPAI). The circulating time of this amplifier is $100 \mathrm{nsec}$. P2 is injected into a second circulating pulse amplifier (CPA2). The circulating time of this amplifier is 99 nsec. A counter that is connected to CPA2 records the number of times that P2 has gone around the loop. Each time that $P 1$ and $P 2$ make a revolution, a detector circuit located at two respective spots in the two CPA's checks to see which pulse ocurred first. As time goes on, P2 will reach the detector circuit first. The time between $\mathrm{Pl}$ and $\mathrm{P2}$ is determined at this time and is the product of the number of revolutions that $P 2$ has made and the difference in circulating times of CPAI and CPA2. 


\section{SYSTEM DESCRIPTION}

The desirable features of the system will be discussed first so that they may be incorporated into the system.

The system to be designed is to measure kinetic energy of neutrons in the range of 0.01 electron-volts (ev) to $0.05 \mathrm{ev}$. Neutrons in this energy range are produced in the Ames Laboratory Research Reactor. Since neutrons of this energy range are used in experiments at Ames Laboratory, it is desirable to determine the relative abundance of neutrons of these different energies.

\section{A. Method}

The method to be used to determine the energy of these neutrons is called the time of flight (TOF) method. That is, if the flight path length, the starting time, and the end of flight time of the neutrons are kriown, then the kinetic energy of these neutrons can be determined.

Timing the flight of neutrons is accomplisthed in the following manner. A neutron chopper is used as a gate to allow neutrons to begin their flight (Figure 1). [Used with the permission of the author of (8).]. The neutrun chopper to be used is cylindrically shaped with alternate layers of material which are opaque and transparent to neutrons. As the chopper is rotated, it will allow ncutrons to pass through it twico every revolution (Figure 2). A light shining on two flat polished surfaces spaced $180^{\circ}$ apart is reflected to a photo diode. The photo diode generates a voltage each time the chopper opens so that the starting time is known. A neutron detector located at the end of the flight path generates a voltage when struck by a neutron. 


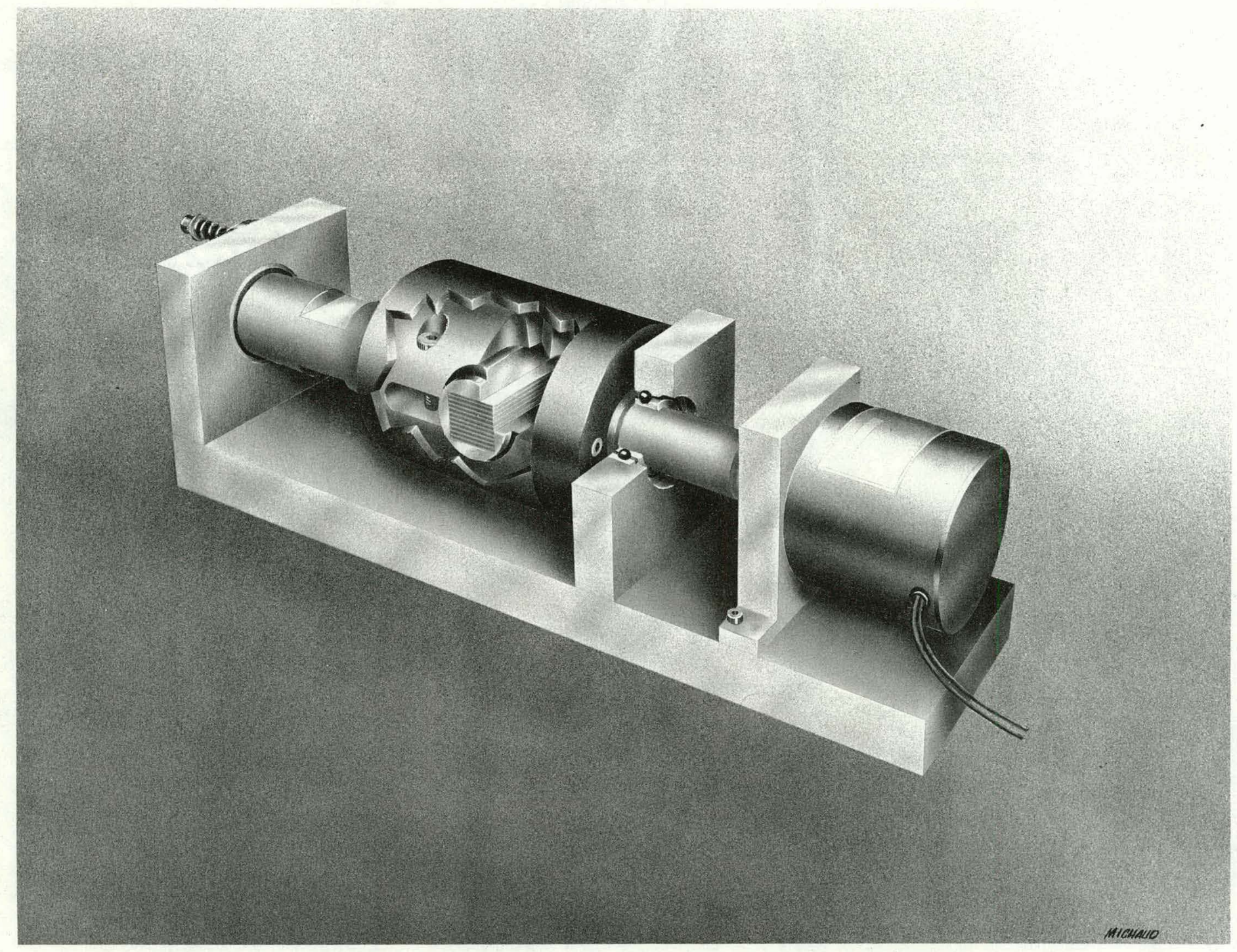

Figure 1. Artist's concept of chopper 


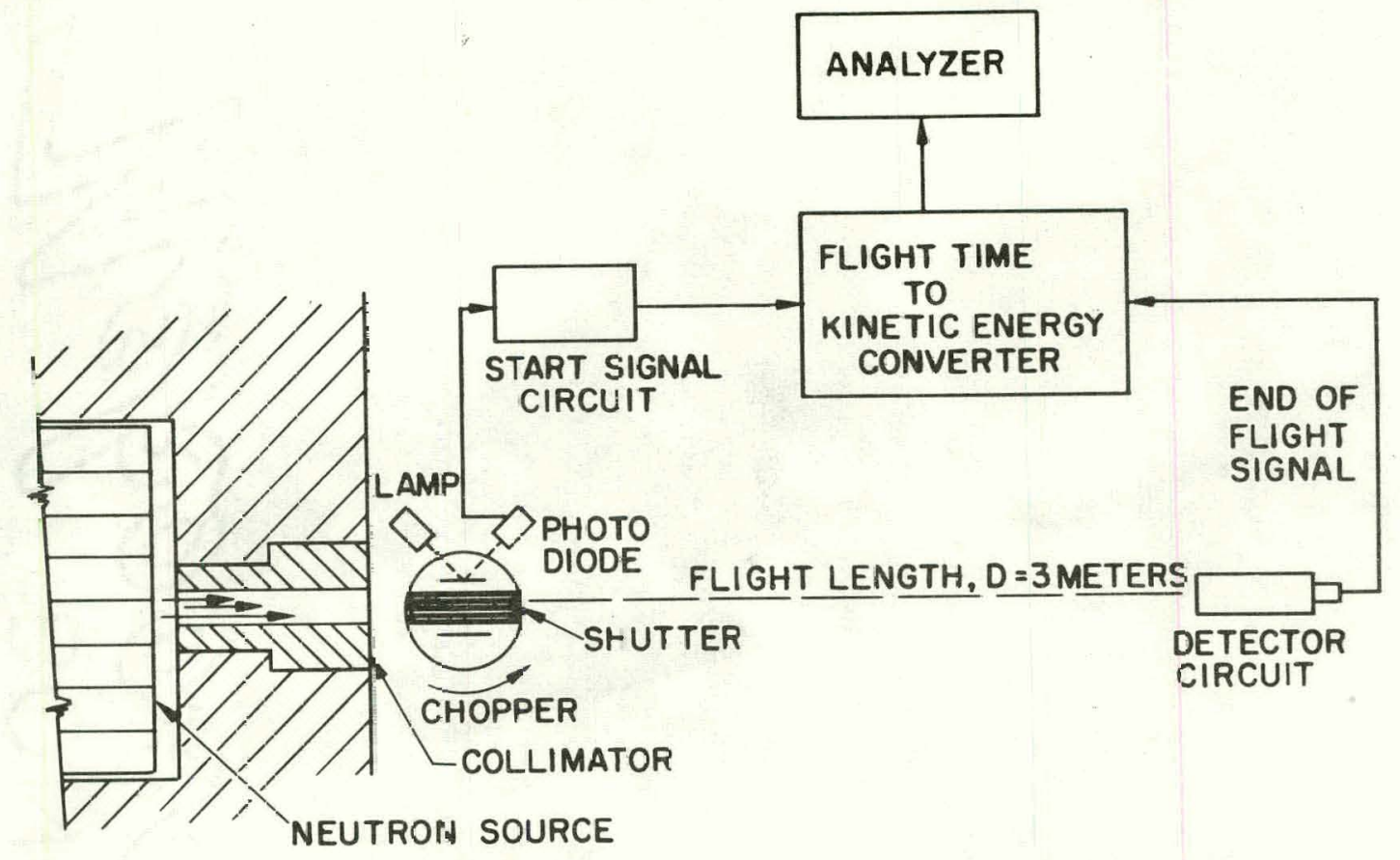

Figure 2. Block diagram of chopper setup 
This voltage pulse indicates the end of flight time. The energy of the neutron is now determined using the flight path length, the starting time, and the end of flight time. The system to be designed is a time of flight to kinetic energy converter.

\section{B. Desired Accuracy}

The total accuracy of the system is to be within $4 \%$ error assuming that the starting time and the end of flight time of the neutrons are known exactly. The system will treat small groups of energies as the same energy, which must be considered part of the error.

\section{Desired Results}

The system to be designed will use a sampling technique. Neutrons within the small energy groups mentioned above will be counted for equal times and this information will be stored until the desired number of groups have been counted.

The output of this system will be information that relates the number of neutrons versus the kinetic energy of these particles. That is, a probability density curve of these neutrons will be known with respect to their kinetic energy.

The system will incorporate a pulse height analyzer which stores information concerning pulse height versus the number of these pulses received during a sampling period. The analyzer then prints this information on paper tape.

The analyzer to be used is a Radiation Instrument Development Laboratory (RIDL) 52-34 which has 400 counters (scalers) or channels and can accept 400 different pulse heights between 0 and 8 volts. 


\section{SYSTEM DESIGN}

\section{A. Flight Time Versus Kinetic Energy}

Since the method to be used to determine kinetic energy is flight time, it is desirable that an expression relating flight time and kinetic energy be developed.

It will be assumed that the energy of the neutron will not change during its flight so tlial,

$$
D=v t
$$

will be valid. $D$ is the length of the flight path in meters, $v$ is the velocity of the neutron in meters per second, and $t$ is the flight time in seconds. The medium in which the neutrons will be traveling is air which makes the above assumption very nearly valid. The starting time will be defined to be when $t=0$.

The kinetic energy of a particle of mass $m$ is given by the equation,

$$
E=1 / 2 m v^{2}
$$

where $E$ is the kinetic energy in joules, $m$ is the mass in kilograms, and $v$ is as defined above.

By solving equations (1) and (2) simultarieously, the energy of the neutron versus flight time $t$ becomes,

$$
E=1 / 2 m D^{2}\left(1 / t^{2}\right)
$$

If $1 / 2 \mathrm{mD}^{2}=\mathrm{K}_{1}$ then

$$
E=K_{1} / t^{2}
$$

The mass of a neutron is: $m=16716.7 \times 10^{-31} \mathrm{kilograms}$ and the flight 
length is: $D=3$ meters.

$\mathrm{K}_{1}$ can now be determined to be:

$$
K_{1}=75225 \times 10^{-31} \sec ^{2} \text {-joules } .
$$

The energy range of interest is $.01 \mathrm{ev}$ to $.05 \mathrm{ev}$ which is $1.602 \times 10^{-21}$

joules to $8.01 \times 10^{-21}$ joules. By the use of equation ( 3 ), the flight time can be determined to range from $0.97 \times 10^{-3}$ sec for $0.05 \mathrm{ev}$ to $2.17 \times 10^{-3}$ sec. for $0.01 \mathrm{ev}$.

\section{B. Fundamental Basis}

If a voltage that was proportional to $k_{1} / t^{2}$ was generated starting at $t=0$, the magnitude of this voltage would be proportional to the kinetic energy of the neutron when it struck the detector at the end of its flight path. This is the fundamental basis for the design of the system.

If the generator voltage were sampled when a neutron struck the detector, a pulse whose magnitude was proportional to the neutron's kinetic energy would be formed. With a pulse height analyzer, the number of pulses of varying magnitudes could be counted and stored. The information that would be obtained would relate kinetic energy density to kinetic energy in a kinetic energy spectrum.

The RIDL 52-34 analyzer stores the number of received voltage pulses in 400 different memory locations (called channels) according to their magnitudes. The relationship of pulse magnitude versus memory location is giveii by

$$
v=0.02 n
$$

where $v$ is in volts and $n$ is the memory location $(1 \leq n \leq 400)$. 


\section{Magnitude of Output Voltage}

It is desirable to choose the voltage waveform that is to be proportional to $k_{l} / t^{2}$ that will utilize most of 8 volts range of the analyzer. The voltage wave form

$$
v=k_{2} / t^{2}
$$

need only be proportional to $k_{1} / t^{2}$ in the range of energies of interest. If $v=7$ volts is made the maximum voltage, this would occur at $t=.97 \times 10^{-3}$ sec $_{\text {eg }}$ then from equation (6)

$$
K_{2}=6.6 \times 10^{-6}
$$

A voltage pulse of 7 volts would be stored in channel 350, equation (5). The minimum voltage occurs at $\mathrm{t}=2.17 \times 10^{-3} \mathrm{sec}$. By using equations (6) and (7)

$$
v=1.41 \text { volts }
$$

The channel which this voltage pulse would be stored in is channel 70 , equation (b). The voltage range of 1.41 volts to 7 volts is fairly large range of the 8 volts available, therefore $k_{2}=6.6 \times 10^{-6}$ will be used for the constant of equation (6).

\section{Kinetic Energy Versus Channel Number}

It is necessary to know what kibelic elielgy is slued ill which cladult of the analyzer. Using equations (3), (5) and (6), an equation of kinetic energy versus channel number $\mathrm{n}$ can be found to be

$$
\mathrm{n}=\frac{\mathrm{K}_{2}}{0.01 \mathrm{mD}^{2}} \mathrm{E} \text {. }
$$

With the values of the constants $m, D$ and $k_{2}$ substituted into equation (9) 
then the kinetic energy in joules versus the storage channel number is

$$
\mathrm{n}=4.4 \times 10^{+22} \mathrm{E}
$$

Since kiretic energy of neutrons is discussed in terms of electron-volts (ev), it would be desirable to express equation (10) so that $E$ would be in ev. One electron-volt is equal to $1.602 \times 10^{-19}$ joules so that

$$
n=7000 E
$$

The resolution that the analyzer can achieve under the present set of assumed conditions can be calculated by determining the difference of kinetic energies stored in two adjacent channels. That is, if

$$
\mathrm{n}_{1}=7000 \mathrm{E}_{1}
$$

and

$$
\mathrm{n}_{2}=7000 \mathrm{E}_{2}
$$

then

$$
E_{1}-E_{2}=\frac{1}{7000}\left(n_{1}-n_{2}\right) \text {. }
$$

But since $\left(n_{1}-n_{2}\right)$ is equal to 1 , then

$$
E_{1}-E_{2}=0.000143 \mathrm{ev}
$$

$E_{1}-E_{2}$ is quite small as compared to $0.05 \mathrm{ev}$. It will, therefore, be assumed that the preceding choice of constants is acceptable.

$$
\text { E. Approximation of } \mathrm{K}_{2} / \mathrm{t}^{2}
$$

In order to design the system thus far described it is necessary to generate the voltage

$$
v=K_{2} / t^{2}
$$

It will be noted that it is impossible to generate an infinite voltage at time equal to zero. If a neulron struck the neutron detector at the end of 
the flight path at $t=0$, then from equation (3) the kinetic energy of that neutron would be infinite. Since the range of kinetic energies of interest lie between $0.01 \mathrm{ev}$ and $0.05 \mathrm{ev}$, it is necessary only to generate this waveform during the time interval of $0.97 \times 10^{-3} \mathrm{sec}$ to $2.17 \times 10^{-3} \mathrm{sec}$.

There are several ways to approximate $v=k_{2} / t^{2}$ with other curves in the previously mentioned time range. The voltage $e_{0}$ across the resistor shown in Figure 3 is

$$
e_{0}=v_{B} e^{-t / R C}
$$

This voltage waveform could be used to fit $v=k_{2} / t^{2}$ as shown in Figure 3 . Another way to approximate the curve $v_{1}=k_{2} / t^{2}$ in the range of interest is to fit it with a stair-step curve. This method is demonstrated in Figure 4. This second method will be the approximation to be used.

\section{F. Error in Output Voltage}

It will be noted that the error between the two curves in Figure 4 decreases as the number of steps (s) is increased. If we differentiate

$$
v=k_{2} / t^{2}
$$

With respect to $t$ we find,

$$
\frac{d v}{d t}=-\frac{2 K_{2}}{\tau}
$$

The greatest rate of change occurs when $t$ is the smallest. Therefore, the maximum error in the stair-step approximation will be in the first interval. The magnitude of each step will be the average of $k_{2} / t^{2}$ evaluated at initial and final time of the interval in which the stair-step occurs. The magnitude of the stair-step in interval 1 is 


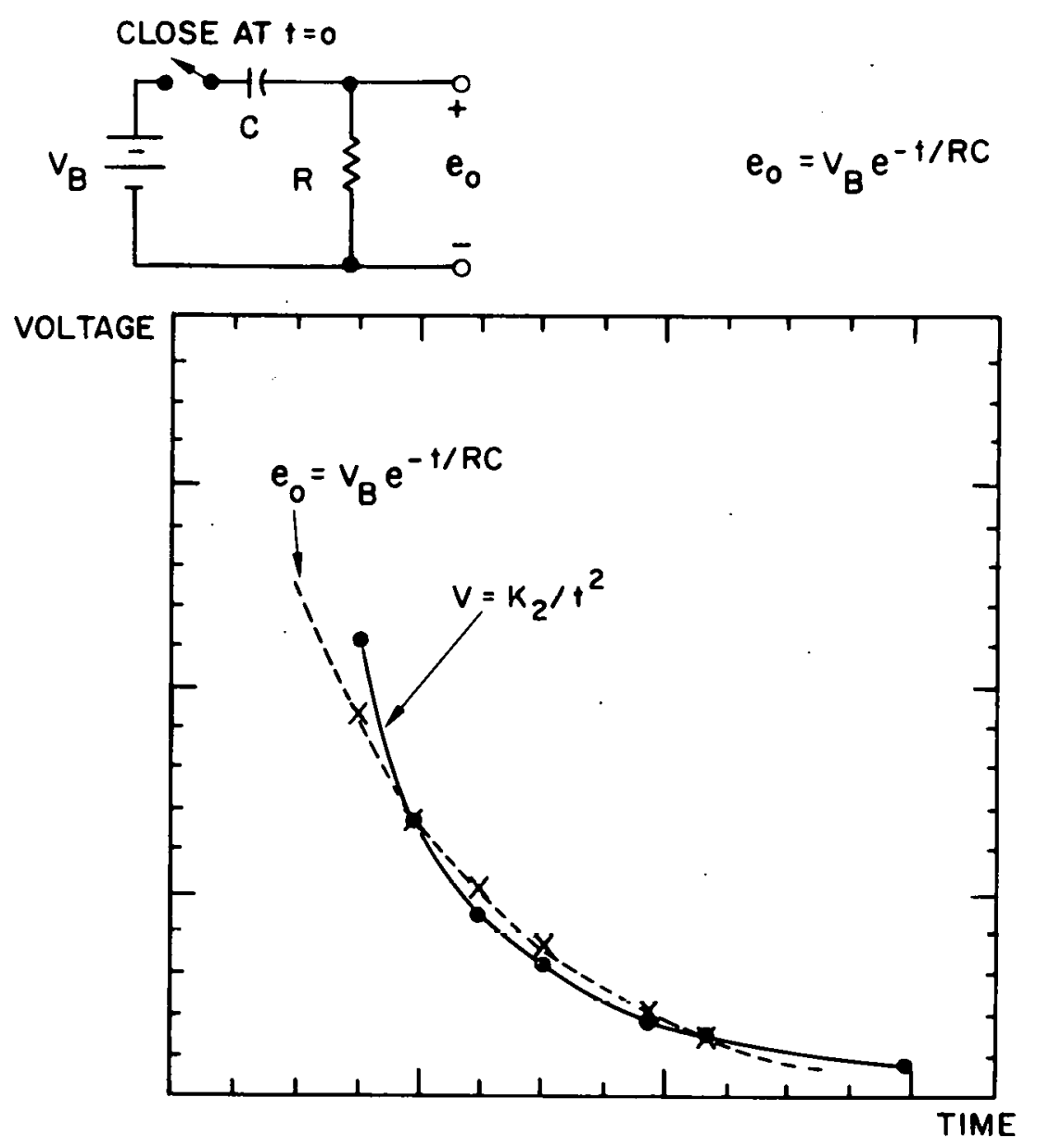

Figure 3. Approximation curve for $k_{2} / t^{2}$ 


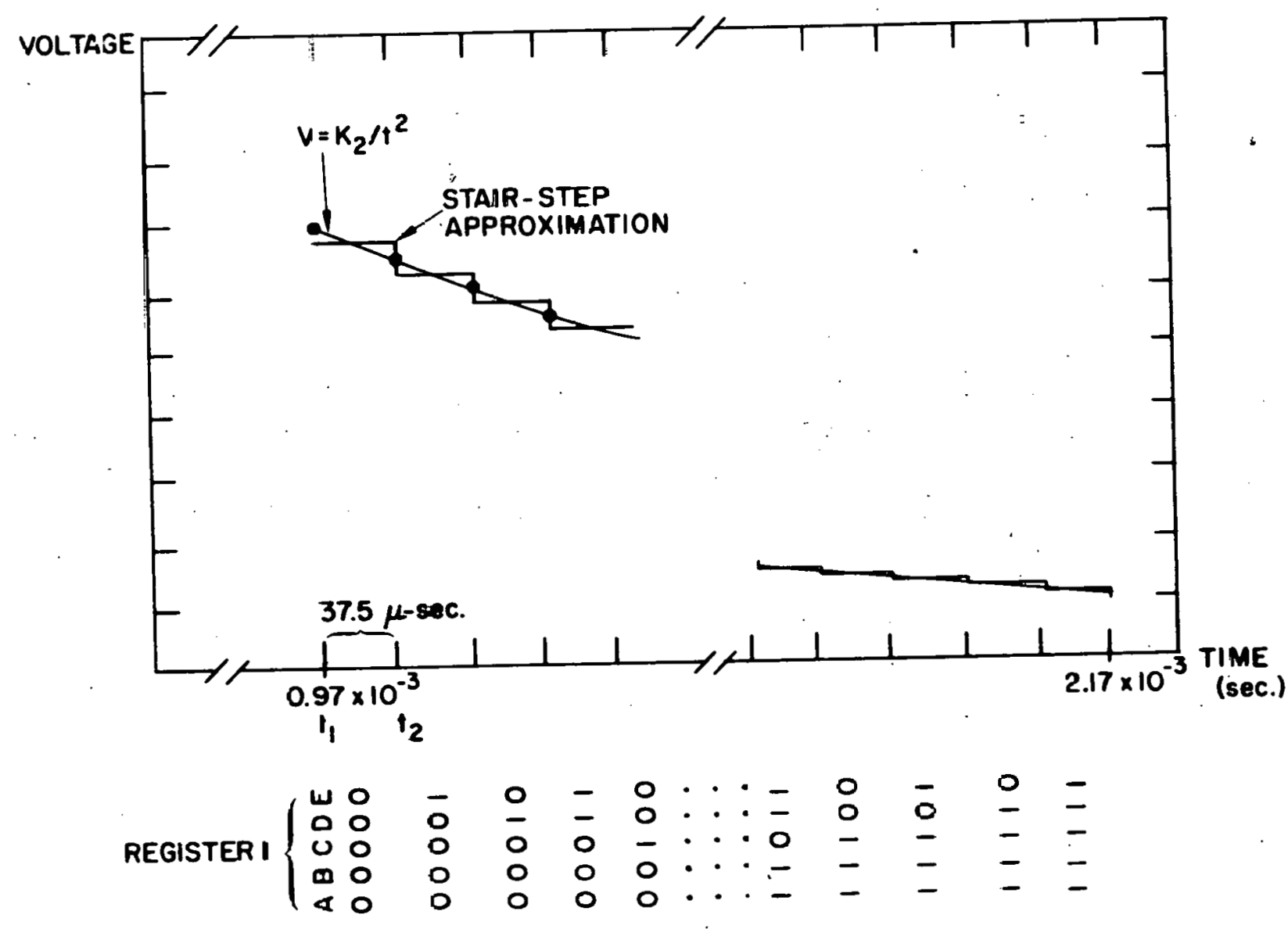

FIgure 4. Stair-step approx mation of $K_{2} / t^{2}$ 


$$
e_{1}=1 / 2 k_{2}\left(1 / t_{1}^{2}+1 / t_{2}^{2}\right)
$$

For uniformly spaced intervals, the length of the interval is the total time divided by the number of intervals (s). Therefore,

$$
t_{2}-t_{1}=\frac{1.2 \times 10^{3}}{s}
$$

The difference between $v$ and $e_{1}$ at $t_{1}$ determines the greatest error that will exist between the two curves.

$$
\text { error }=k_{2} / t_{1}^{2}-1 / 2 k_{2}\left(1 / t_{1}^{2}+1 / t_{2}^{2}\right)
$$

The percentage of error is,

$$
\% \text { error }=100 \frac{1 / 2 k_{2}\left(1 / t_{1}{ }^{2}-1 / t_{2}{ }^{2}\right)}{k_{2} / t_{1}{ }^{2}}=50\left(1-t_{1}{ }^{2} / t_{2}{ }^{2}\right)
$$

The percentage of error in terms of the number of steps $S$ can be determined by using equations (13) and (15) and by letting $t_{1}$ be $0.97 \times 10^{-3} \mathrm{sec}$.

$$
\% \text { error }=50-\frac{47 \times 10^{-6}}{\left(.97 \times 10^{-3}+\frac{1.2 \times 10^{-3}}{5}\right)^{2}}
$$

If the number of steps $S$ is set equal to 16 , then the

$$
\% \text { error }=7.06 \%
$$

If the number of steps is increased to 32 then the

$$
\% \text { error }=3.35 \%
$$

If the number of steps is increased to 64 then the

$$
\% \text { error }=2.47 \% \text {. }
$$


The number of steps to be used in this system is 32 .

\section{G. Method of Generating the Output Voltage}

It is now necessary to develop a circuit that will produce this stairstep function.

Consider the circuit shown in Figure 5. In this simple voltage divider circuit, the output voltage $e_{k}$ is given by,

$$
e_{k}=-E \frac{\sum_{k} R_{i}}{\sum_{K}^{33} R_{i}}, K=(1,2, \ldots 32)
$$

where $K$ is the number of the only switch closed. When $K$ is set equal to 1 is defined to be when all the switches are open. If the switches are closed in sequence with equal time spacing, from 2 to 32 then a stair-step voltage waveform is generated. If the resistors in this voltage divider circuit are chosen correctly; the voltage waveform will approximate

$$
v=k_{2} / t^{2}
$$

as shown in Figure 4.

It will be recalled that when the error in the stair-step approximation was determined, the voltage of the first step was determined to be the average of $\mathrm{K}_{2} / \mathrm{t}^{2}$ at the initial and final times of the interval. This method will be used to determine the voltage of each of the steps. The voltage of each stair-step is then 


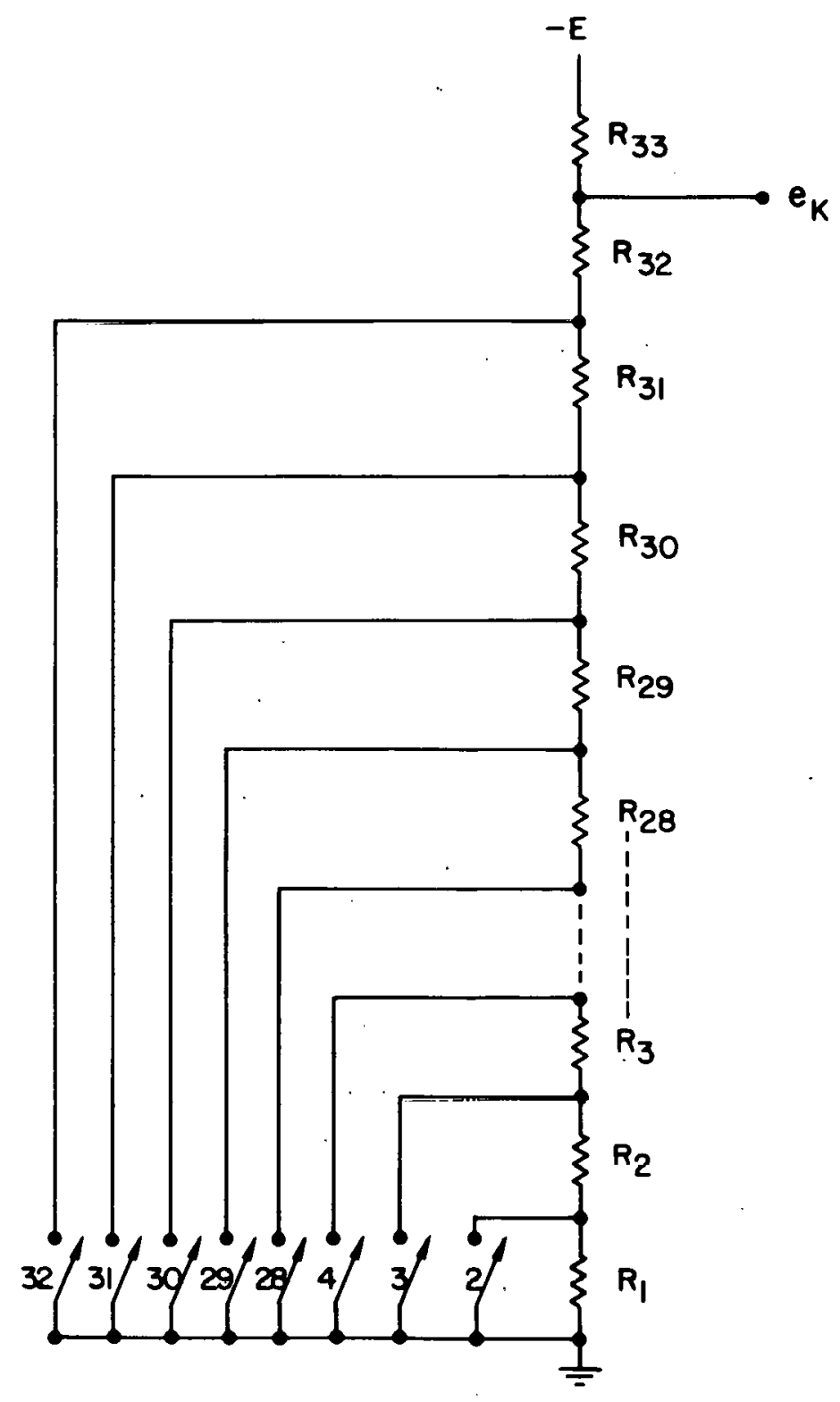

Figure 5. Voltage divider circuit 


$$
e_{k}=1 / 2 k_{2}\left[\frac{1}{\left[t_{1}+(k-1) \Delta t\right]^{2}}+\frac{1}{\left[t_{1}+k \Delta t\right]^{2}}\right], K=(1,2 \ldots 32)
$$

where $\Delta t$ is the width of each interval given by equation (13) with $S=32$. A computer program gave the following values for $e_{k}$ shown in Table 1.

Table 1. Computer calculations for $e_{k}$

\begin{tabular}{llrl}
\hline$e_{1}=6.758$ & $e_{12}=3.363$ & $e_{23}=2.001$ \\
$e_{2}=6.273$ & $e_{13}=3.190$ & $e_{24}=1.926$ \\
$e_{3}=5.838$ & $e_{14}=3.030$ & $e_{25}=1.051$ \\
$e_{4}=5.447$ & $e_{15}=2.882$ & $e_{26}=1.779$ \\
$e_{5}=5.094$ & $e_{16}=2.744$ & $e_{27}=1.712$ \\
$e_{6}=4.774$ & $e_{17}=2.616$ & $e_{28}=1.648$ \\
$e_{7}=4.483$ & $e_{18}=2.497$ & $e_{29}=1.588$ \\
$e_{8}=4.218$ & $e_{19}=2.385$ & $e_{30}=1.531$ \\
$e_{9}=3.976$ & $e_{20}=2.281$ & $c_{31}=1.478$ \\
$e_{10}=3.755$ & $e_{21}=2.184$ & $e_{32}=1.426$ \\
$e_{11}=3.551$ & $e_{22}=2.093$ &
\end{tabular}

With the value of $e_{k}$ for each step specified, it is necessary to determine the resistor values in the voltage divider circuit. It will be hoted with switch 32 closed the output voltage as given by equation (16) is

$$
e_{32}=-E \frac{R_{32}}{R_{32}+R_{33}}
$$

With $E=12$ volts, $e_{32}=1.426$ volts and $R_{32}=1 K$, then $R_{33}$ can be calculated. If switch 31 is now closed with 32 open, then by equation (16) 


$$
e_{31}=-E \frac{R_{31}+R_{32}}{R_{31}+R_{32}+R_{33}}
$$

It will be noted that only one new unknown $R_{3 l}$ was added to $e_{K}$. By the method of closing one switch at a time from $k=32$ to $k=2$, only one u.jknown is introduced at a time and can be determined easily. The same computer progran that calculated the values for $e_{k}$ calculated the following values $R_{1}$ through $R_{33}$ shown in Table 2 .

Table 2. Computer calculations for $R_{1}-R_{33}$

\begin{tabular}{llll}
\hline Calculated & Used & Calculated & Used \\
\hline$R_{1}=1438.2$ & 1430 & $R_{18}=108.4$ & 107 \\
$R_{2}=1096.1$ & 1100 & $R_{19}=99.1$ & 100 \\
$R_{3}=861.7$ & 866 & $R_{20}=90.8$ & 90.9 \\
$R_{4}=694.1$ & 698 & $R_{21}=83.5$ & 82.5 \\
$R_{5}=570.1$ & 576 & $R_{22}=77.0$ & 76.8 \\
$R_{6}=475.9$ & 475 & $R_{23}=71.1$ & 71.5 \\
$R_{7}=402.8$ & 402 & $R_{24}=65.9$ & 65.5 \\
$R_{8}=344.9$ & 348 & $R_{25}=61.2$ & 61.9 \\
$R_{10}=260.1$ & 261 & $R_{26}=56.9$ & 57.6 \\
$R_{11}=228.7$ & 226 & $R_{27}=53.1$ & 53.6 \\
$R_{12}=202.4$ & 200 & $R_{28}=50.0$ & 49.9 \\
$R_{13}=180.2$ & 182 & $R_{29}:=46.4$ & 46.4 \\
$R_{14}=161.3$ & 162 & $R_{30}=43.5$ & 43.2 \\
$R_{15}=145.1$ & 147 & $R_{31}=40.8$ & 41.2 \\
$R_{16}=131.1$ & 130 & $R_{32}=1000$ & 1000 \\
$R_{17}=119.0$ & 118 & $R_{33}=7412.4$ & 7400 \\
\hline
\end{tabular}

The values of the $1 \%$ resistors used in the system are tabulated with the values calculated by the computer.

The switches shown in Figure 5 will be transistors operating in their saturation and cutoff modes. In order to obtain a low DC saturation and a 
high cutoff resistance, the transistors will be used in its inverted configuration with the collector and emitter interchanged. The base and the collector then serve as the base and emitter.

Shown in Figure 6, A, B, C and D are transistor curves for 2 404 in its normal and inverted modes. For fast switching action, it is desirable to saturate the transistor with the smallest base current. In $A$ and $B$ of Figure 6, if the collector emitter current needed to be 1 ma for saturation, the two top curves would be used. Note that the inverted translstor curve in the saturation region has a greater slope indicating that its saturation resistance is less. Shown in $C$ and $D$ of the same figure are the transistor curves of 2 N404 on a different scale. It can be seen that the cutoff resistance of the inverted transistor is greater. Shown in Figure 7 is the voltage divider circuit with the inverted switching transistors. To instrument the sequence for the switching action, a register composed of 5 flip-flops will be used (Figure 12). This register (register 1) will be advanced from: a clock (clock l) of constant frequency. The states of the 5 flip-flops will be decoded and applied to the base resistors of the switching transistors so that as the register is advanced the transistors saturate in sequence from $T_{2}$ to $T_{32}$.

With the dofinition that a logical "l" is -12 volts and a logical "0"' is 0 volts, it is evident that a "l" must be present at the base resistors of the switching transistors to make. them salurate. Shown in Table 3 are the states of register 1 and the inputs $\left(z_{2}-z_{32}\right)$ to the base resistors of the switching transistors. Note that it makes little difference whether a switching transistor is saturated or cutoff after the time interval in which it is to saturate. This is true because one of the transistors above this 

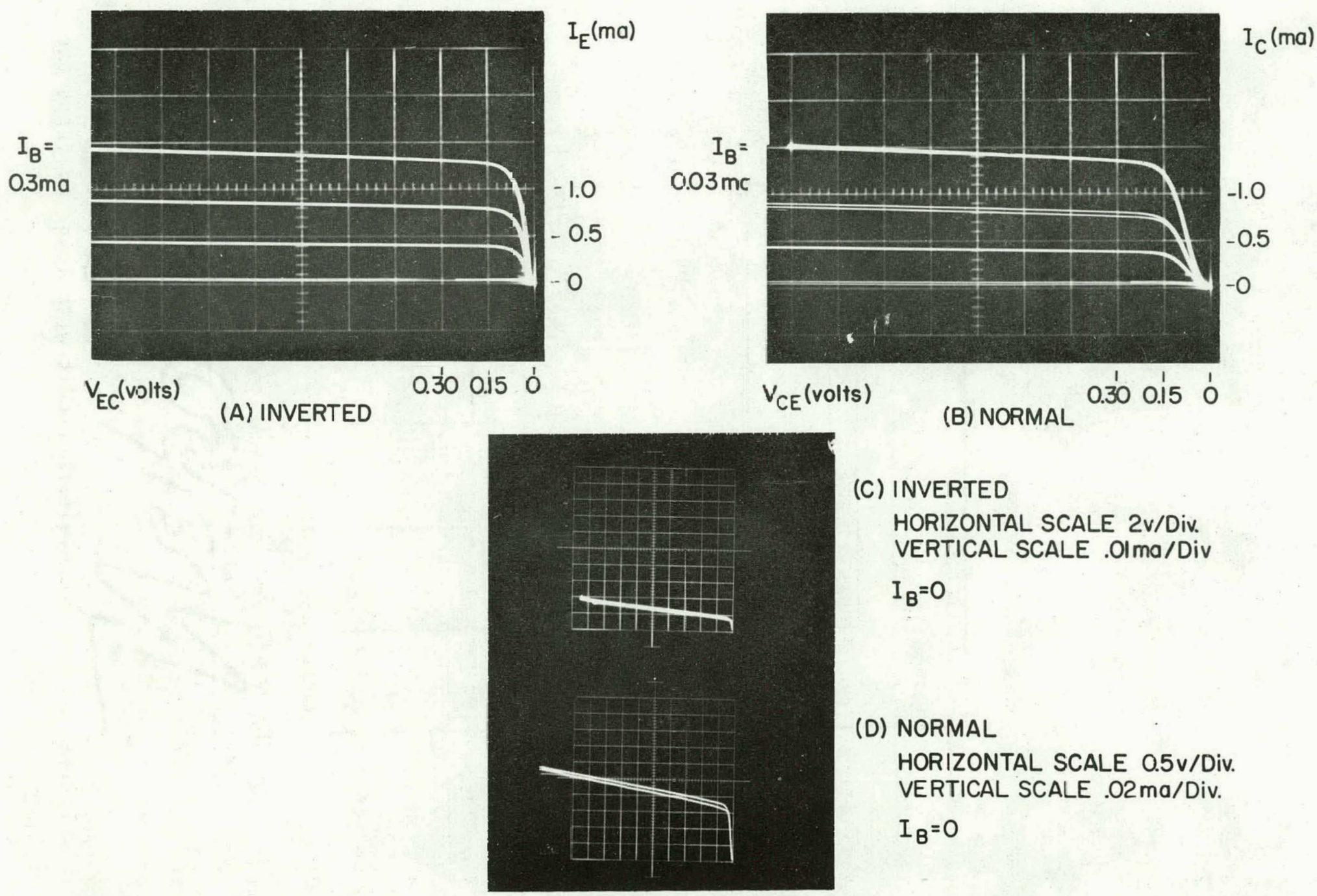

(C) INVERTED

HORIZONTAL SCALE 2v/Div. VERTICAL SCALE .OIma/Div $I_{B}=0$

(D) NORMAL

HORIZONTAL SCALE 0.5v/Div. VERTICAL SCALE .02ma/Div. $I_{B}=0$

Figure 6. Transistor curves for $2 \mathrm{~N} 404$ 


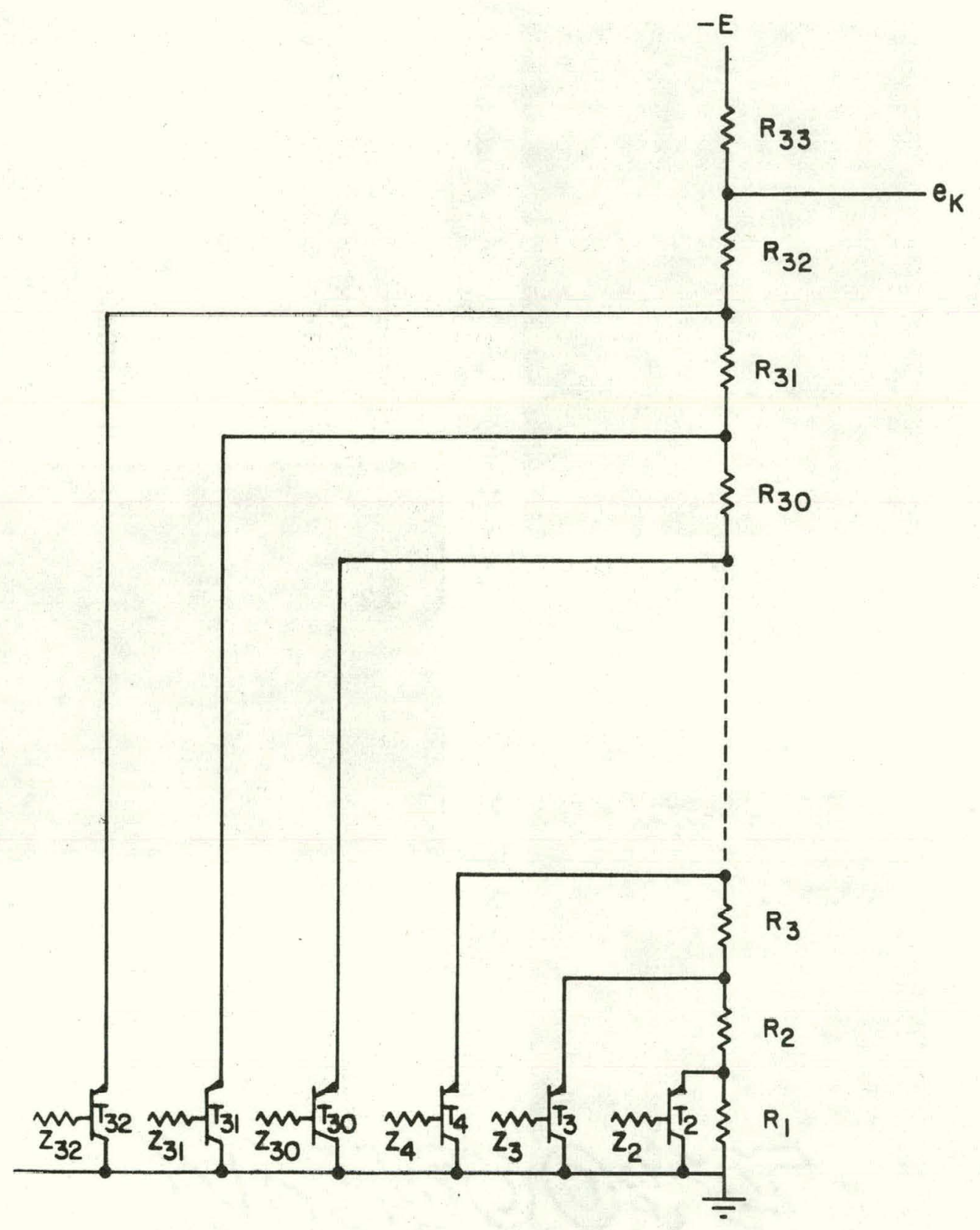

Figure 7. Voltage divider circuit with inverted transistors 
Table 3. Truth table for switching transistors

\begin{tabular}{|c|c|c|c|c|c|c|c|c|c|c|c|c|c|c|c|c|c|c|c|c|c|c|c|c|c|c|c|c|c|c|c|c|c|c|}
\hline \multicolumn{11}{|c|}{ Register 1} & \multicolumn{24}{|c|}{ Base Resistor Inputs $\left(z_{2}-z_{32}\right)$} \\
\hline & $\frac{3}{0} \cdot \frac{c}{0}$ & $\underline{D}$ & & $\frac{2}{0}$ & $\frac{3}{0}$ & $\frac{4}{0}$ & $\frac{5}{0}$ & $\frac{6}{0}$ & $\frac{7}{0}$ & $\frac{8}{0}$ & & $\frac{10}{0}$ & & $\frac{12}{0}$ & & & & & & & & & $\frac{21}{0}$ & $\frac{22}{0}$ & & $\frac{24}{0}$ & $\frac{25}{0}$ & & 27 & & & & & $\frac{32}{0}$ \\
\hline $0 \mathrm{c}$ & 0 & 0 & & 1 & 0 & 0 & 0 & 0 & 0 & 0 & 0 & 0 & 0 & 0 & 0 & 0 & 0 & 0 & 0 & 0 & 0 & 0 & 0 & 0 & 0 & 0 & 0 & 0 & 0 & 0 & 0 & 0 & 0 & \\
\hline 0 & 00 & 1 & & $x$ & 1 & 0 & 0 & 0 & 0 & 0 & 0 & 0 & 0 & 0 & 0 & 0 & 0 & 0 & 0 & 0 & 0 & 0 & 0 & 0 & 0 & 0 & 0 & 0 & 0 & 0 & 0 & 0 & 0 & \\
\hline 0 & 00 & 1 & & $x$ & $x$ & 1 & 0 & 0 & 0 & 0 & 0 & 0 & 0 & 0 & 0 & 0 & 0 & 0 & 0 & 0 & 0 & 0 & 0 & 0 & 0 & 0 & 0 & 0 & 0 & 0 & 0 & 0 & 0 & \\
\hline 0 & & & 0 & $x$ & $x$ & $X$ & 1 & 0 & 0 & 0 & 0 & 0 & 0 & 0 & 0 & 0 & 0 & 0 & 0 & 0 & 0 & 0 & 0 & 0 & 0 & 0 & 0 & 0 & 0 & 0 & 0 & 0 & 0 & \\
\hline 0 & & & 1 & $x$ & $x$ & $X$ & $x$ & 1 & 0 & 0 & 0 & 0 & 0 & 0 & 0 & 0 & 0 & 0 & 0 & 0 & 0 & 0 & 0 & 0 & 0 & 0 & 0 & 0. & 0 & 0 & 0 & 0 & 0 & \\
\hline 0.0 & 01 & 1 & 0 & $x$ & $x$ & $x$ & $x$ & $x$ & 1 & 0 & 0 & 0 & 0 & 0 & 0 & 0 & 0 & 0 & 0 & 0 & 0 & 0 & 0 & 0 & 0 & 0 & 0 & 0 & 0 & 0 & 0 & 0 & 0 & \\
\hline 00 & 01 & 1 & & $x$ & $x$ & $x$ & $x$ & $x$ & $x$ & 1 & 0 & 0 & 0 & 0 & 0 & 0 & 0 & 0 & 0 & 0 & 0 & 0 & 0 & 0 & 0 & 0 & 0 & 0 & 0 & 0 & 0 & 0 & 0 & \\
\hline 0 & 10 & 0 & 0 & $x$ & $x$ & $X$ & $x$ & $x$ & $x$ & $X$ & 1 & 0 & 0 & 0 & 0 & 0 & 0 & 0 & 0 & 0 & 0 & 0 & 0 & 0 & 0 & 0 & 0 & 0 & 0 & 0 & 0 & 0 & 0 & \\
\hline 0 & 10 & 0 & 1 & $x$ & $x$ & $x$ & $x$ & $x$ & $x$ & $x$ & $x$ & 1 & 0 & 0 & 0 & 0 & 0 & 0 & 0 & 0 & 0 & 0 & 0 & 0 & 0 & 0 & 0 & 0 & 0 & 0 & 0 & 0 & 0 & \\
\hline 0 & 10 & 1 & 0 & $x$ & $x$ & $X$ & $x$ & $x$ & $x$ & $x$ & $x$ & $x$ & 1 & 0 & 0 & 0 & 0. & 0 & 0 & 0 & 0 & 0 & 0 & 0 & 0 & 0 & 0 & 0 & 0 & 0 & 0 & 0 & 0 & \\
\hline 01 & 10 & 1 & 1 & $x$ & $x$ & $x$ & $x$ & $x$ & $x$ & $x$ & $x$ & $x$ & $x$ & 1 & 0 & 0 & 0 & 0 & 0 & 0 & 0 & 0 & 0 & 0 & 0 & 0 & 0 & 0 & 0 & 0 & 0 & 0 & 0 & \\
\hline 01 & 11 & 0 & 0 & $x$ & $x$ & $x$ & $x$ & $x$ & $x$ & $x$ & $x$ & $x$ & $x$ & $x$ & 1 & 0 & 0 & 0 & 0 & 0 & 0 & 0 & 0 & 0 & 0 & 0 & 0 & 0 & 0 & 0 & 0 & 0 & 0 & \\
\hline 01 & 11 & 0 & 1 & $x$ & $x$ & $X$ & $x$ & $X$ & $x$ & $x$ & $x$ & $x$ & $x$ & $x$ & $X$ & 1 & 0 & 0 & 0 & 0 & 0 & 0 & 0 & 0 & 0 & 0 & 0 & 0 & 0 & 0 & 0 & 0 & 0 & \\
\hline 0 & 11 & 1 & & $x$ & $x$ & $x$ & $x$ & $x$ & $x$ & $x$ & $x$ & $x$ & $X$ & $x$ & $x$ & $x$ & 1 & 0 & 0 & 0 & 0 & 0 & 0 & 0 & 0 & 0 & 0 & 0 & 0 & 0 & 0 & 0 & 0 & \\
\hline 01 & 11 & 1 & 1 & $x$ & $x$ & $x$ & $x$ & $x$ & $x$ & $x$ & $x$ & $x$ & $X$ & $x$ & $x$ & $x$ & $x$ & 1 & 0 & 0 & 0 & 0 & 0 & 0 & 0 & 0 & 0 & 0 & 0 & 0 & 0 & 0 & 0 & \\
\hline 1.0 & & 0 & 0 & $x$ & $x$ & $x$ & $x$ & $x$ & $x$ & $x$ & $x$ & $x$ & $x$ & $x$ & $x$ & $x$ & $x$ & $x$ & 1 & 0 & 0 & 0 & 0 & 0 & 0 & 0 & 0 & 0 & 0 & 0 & 0 & 0 & 0 & \\
\hline 10 & 0 & 0 & 1 & $X$ & $X$ & $X$ & $X$ & $X$ & $x$ & $x$ & $x$ & $x$ & $x$ & $x$ & $x$ & $x$ & $x$ & $x$ & $x$ & 1 & 0 & 0 & 0 & 0 & 0 & 0 & 0 & $0^{\circ}$ & 0 & 0 & 0 & 0 & 0 & \\
\hline 10 & 0 & 1 & 0 & $x$ & $x$ & $x$ & $x$ & $x$ & $x$ & $x$ & $x$ & $x$ & $x$ & $x$ & $x$ & $x$ & $x$ & $x$ & $x$ & $x$ & 1 & 0 & 0 & 0 & 0 & 0 & 0 & 0 & 0 & 0 & 0 & 0 & 0 & \\
\hline 10 & 0 & 1 & 1 & $x$ & $x$ & $x$ & $x$ & $x$ & $x$ & $x$ & $x$ & $x$ & $x$ & $x$ & $X$ & $x$ & $x$ & $x$ & $x$ & $X$ & $x$ & 1 & 0 & 0 & 0 & 0 & 0 & 0 & 0 & 0 & 0 & 0 & 0 & \\
\hline 10 & 1 & 0 & 0 & $x$ & $X$ & $x$ & $x$ & $X$ & $x$ & $x$ & $x$ & $x$ & $x$ & $x$ & $X$ & $X$ & $X$ & $x$ & $x$ & $x$ & $x$ & $X$ & 1 & 0 & 0 & 0 & 0 & 0 & 0 & 0 & 0 & 0 & 0 & \\
\hline 10 & 1 & 0 & 1 & $x$ & $x$ & $x$ & $x$ & $x$ & $x$ & $x$ & $x$ & $x$ & $x$ & $x$ & $x$ & $x$ & $x$ & $x$ & $x$ & $x$ & $x$ & $x$ & $x$ & 1 & 0 & 0 & 0 & 0 & 0 & 0 & 0 & 0 & 0 & \\
\hline 10 & 01 & 1 & 0 & $x$ & $x$ & $x$ & $x$ & $x$ & $x$ & $x$ & $x$ & $x$ & $x$ & $x$ & $x$ & $x$ & $x$ & $x$ & $x$ & $x$ & $x$ & $x$ & $x$ & $x$ & 1 & 0 & 0 & 0 & 0 & 0 & 0 & 0 & 0 & \\
\hline 10 & 1 & 1 & 1 & $x$ & $x$ & $x$ & $x$ & $x$ & $x$ & $x$ & $x$ & $x$ & $x$. & $x$ & $x$ & $x$ & $x$ & $x$ & $x$ & $x$ & $x$ & $x$ & $x$ & $x$ & $x$ & 1 & 0 & 0 & 0 & 0 & 0 & 0 & 0 & \\
\hline 11 & 10 & 0 & 0 & $x$ & $x$ & $x$ & $x$ & $x$ & $x$ & $x$ & $x$ & $x$ & $x$ & $x$ & $X$ & $x$ & $X$ & $x$ & $x$ & $x$ & $x$ & $x$ & $x$ & $x$ & $x$ & $x$ & 1 & 0 & 0 & 0 & 0 & 0 & 0 & \\
\hline 11 & & 0 & 1 & $x$ & $x$ & $x$ & $x$ & $x$ & $x$ & $x$ & $x$ & $x$ & $x$ & $x$ & $X$ & $x$ & $x$ & $X$ & $x$ & $X$ & $x$ & $x$ & $x$ & $x$ & $x$ & $x$ & $x$ & 1 & 0 & 0 & 0 & 0 & 0 & \\
\hline 11 & 10 & 1 & 0 & $x$ & $x$ & $x$ & $X$ & $x$ & $x$ & $x$ & $x$ & $x$ & $x$ & $x$ & $x$ & $x$ & $x$ & $x$ & $x$ & $x$ & $x$ & $x$ & $x$ & $x$ & $x$ & $x$ & $x$ & $X$ & 1 & 0 & 0 & 0 & 0 & \\
\hline 11 & & 1 & 1 & $x$ & $x$ & $x$ & $x$ & $x$ & $X$ & $x$ & $x$ & $x$ & $x$ & $x$ & $x$ & $x$ & $X$ & $x$ & $X$ & $x$ & $x$ & $x$ & $x$ & $X$ & $x$ & $x$ & $x$ & $x$ & $x$ & 1 & 0 & 0 & 0 & \\
\hline 11 & 11 & 0 & 0 & $x$ & $x$ & $x$ & $x$ & $x$ & $X$ & $x$ & $x$ & $x$ & $x$ & $x$ & $x$ & $x$ & $X$ & $x$ & $X$ & $X$ & $X$ & $x$ & $x$ & $X$ & $x$ & $x$ & $x$ & $X$ & $x$ & $X$ & 1 & 0 & 0 & \\
\hline 11 & 11 & & 1 & $x$ & $x$ & $x$ & $x$ & $x$ & $x$ & $x$ & $X$ & $x$ & $X$ & $X$ & $X$ & $x$ & $X$ & $X$ & $X$ & $x$ & $x$ & $x$ & $x$ & $X$ & $x$ & $x$ & $x$ & $X$ & $x$ & $X$ & $x$ & 1 & 0 & \\
\hline 1 & 11 & 1 & 0 & $x$ & $x$ & $x$ & $x$ & $x$ & $x$ & $x$ & $x$ & $x$ & $x$ & $x$ & $x$ & $x$ & $X$ & $X$ & $x$ & $x$ & $x$ & $x$ & $x$ & $x$ & $x$ & $x$ & $x$ & $x$ & $x$ & $x$ & $x$ & $x$ & 1 & \\
\hline & 1.1 & & & $x$ & $x$ & $x$ & $x$ & $x$ & $x$ & $x$ & $x$. & $x$ & $x$ & $x$ & $x$ & $x$ & $x$ & $x$ & $x$ & $x$ & $x$ & $X$ & $x$ & $X$ & $x$ & $x$ & $x$ & $x$ & $x$ & $x$ & $x$ & $x$ & $x$ & \\
\hline
\end{tabular}


transistor on the voltage divider is saturated. This leads to "don't care" terms (indicated by $X^{\prime} s$ ) in table 3 .

The logical expressions for $z_{2}-z_{32}$ were obtained through the use of veitch diagrams from the truth table for the switching transistors. Most of the logical expressions could be reduced through the use of "don't care" terms. The logical expressions are tabulated below in Table 4.

Table 4. Logical expressions for $z_{2}-z_{32}$

\begin{tabular}{lll}
\hline$z_{2}=\mathrm{E}$ & $z_{12}=\mathrm{BDE}$ & $z_{23}=A C D$ \\
$z_{3}-\mathrm{D}$ & $z_{13}=\mathrm{BC}$ & $z_{24}=A C D E$ \\
$z_{4}=\mathrm{DE}$ & $z_{14}=\mathrm{BCE}$ & $z_{25}=A B \bar{C}$ \\
$z_{5}=\mathrm{C}$ & $z_{15}=\mathrm{BCD}$ & $z_{26}=A B \overline{C E}$ \\
$z_{6}=\mathrm{CE}$ & $z_{16}=\mathrm{BCDE}$ & $z_{27}=A B \overline{C D}$ \\
$z_{7}=\mathrm{CD}$ & $z_{17}=A$ & $z_{28}=A B \overline{C D E}$ \\
$z_{8}=C D E$ & $z_{18}=A E$ & $z_{29}=A B C$ \\
$z_{9}=B$ & $z_{19}=A D$ & $z_{30}=A B C E$ \\
$z_{10}=B E$ & $z_{20}=A D E$ & $z_{31}=A B C D$ \\
$z_{11}=B D$ & $z_{21}=A C$ & $z_{32}=A B C D E$
\end{tabular}

The above logic was built with the use of NOR circuits as shown in Figure 8. If the inputs to a nor are $\bar{A}, \bar{B}$ and $\bar{C}$, the expression can be reduced as shown.

$$
\text { OUTPUT }=\overline{(\bar{A}+\bar{B}+\bar{C})}=A B C
$$

Since the logical expressions $\left(z_{2}-z_{32}\right)$ are "and" functions of the variables, then the "nots" of these variables must be applied to the inputs 


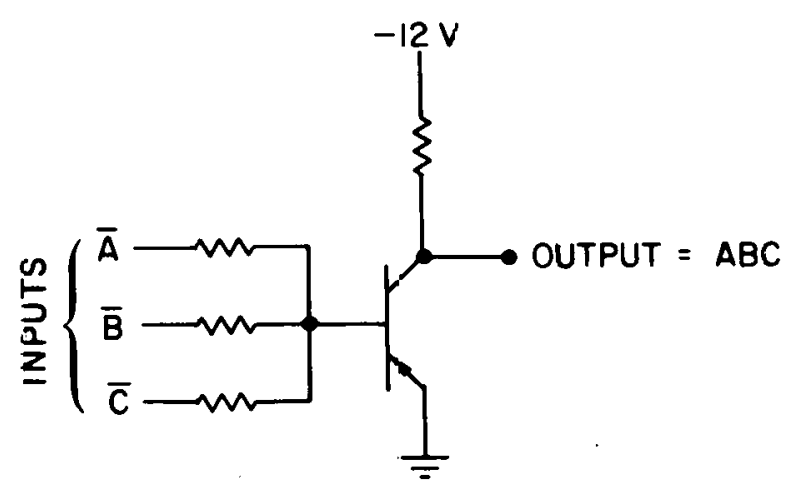

NOR CIRCIUT

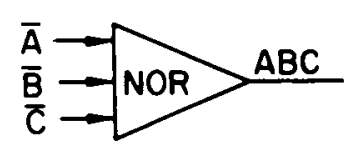

LOGICAL NOR

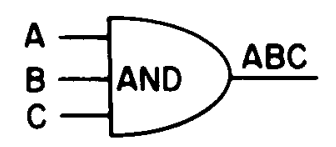

Figure 8. Logical NOR circuit 
of the nor circuit to obtain the correct output.

\section{H. Timing Circuit}

With the system in operation, clock 1 advances register 1 every 1.354

sec. Therefore, the stair-step curve will not approximate $k_{2} / t^{2}$ in the previously assumed time range. The timing must then be instrumented in a different manner. Another register (register 2) is used to do the timing. A second clock (clock 2) is uṣed to advance register 2 (see Figure 12). The period of clock 2 must be equal to the width of each of the 32 intervals. r rom equation (13) the width of the interval is $t_{2}-t_{1}$ with $s=32$.

$$
t_{2}-t_{1}=37.5 \mu \sec .
$$

Clock 2 is a free running multivibrator with a period of $37.5 \mu \mathrm{sec}$.

Neutrons in the energy range of interest arrive at the detector between $0.97 \times 10^{-3}$ and $2.17 \times 10^{-3}$ sec. after the neutron chopper opens at $t=0$. It is for this reason that a time delay of $.97 \times 10^{-3} \mathrm{sec}$. must pass before the system responds to neutrons striking the detector. To instrument this time delay, register 2 and clock 2 are used. Twenty-six periods of clock 2 is $0.975 \times 10^{-3}$ sec. This time, as compared with $0.97 \times 10^{-3}$ sec., represents an error of $0.51 \%$ which can be neglected. The timing diagram for register 2 (Figure 9). shows register 2 set to 00101 and $L=" 0 "$ until $t=0$. After 27 clock 2 pulses (26 time intervals) L changes to "1" and register 2 is 00000. The end of the time delay is indicated by $L$ changing from "0" to "l". For the next 32 time intervals $L$ remains at "l". Note that during this time register 2 has the same state as was first assumed for register 1. It can be clearly seen that when register 1 matches register 2 during this time that the output voltage from the voltage divider circuit is valid and is 

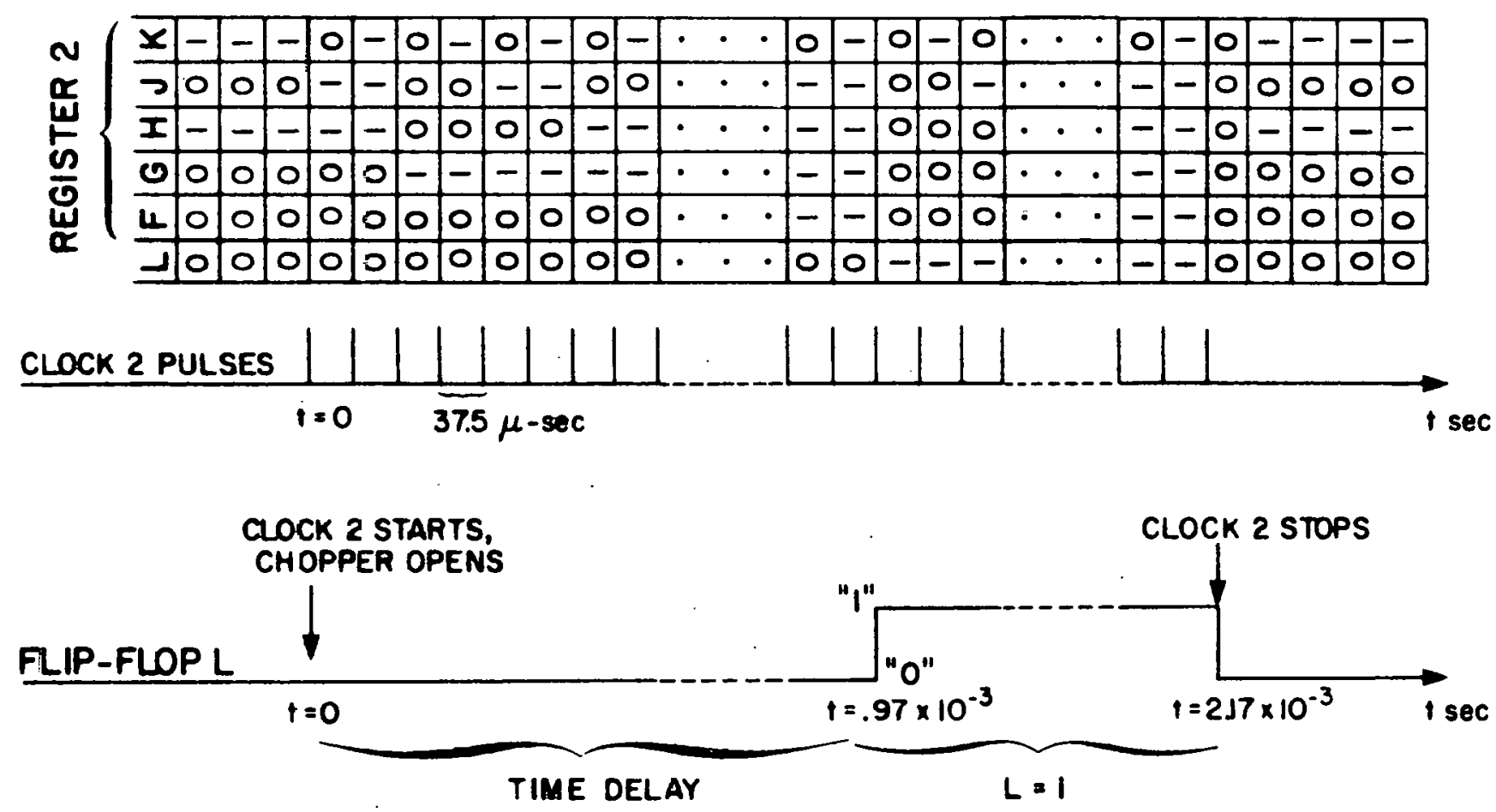

Figure 9. Timing diagram for register 2 
proportional to the kinetic energy of neutrons striking the detector at that time. At the end of the 32 time intervals clock 2 turns itself off on the next clock 2 pulse after register 2 reaches 11111 and $L=" 1 "$ (Figure 10). The last clock 2 pulse sets register 2 to 00000 and $L$ to "0". When this state is detected register 2 is immediately set to 00101 and $L$ remains at "0". Clock 2 is then started again when the neutron chopper reopens if register 2 is 00101 and $L$ is "0" (Figure 10).

The result of advaricing Ieyisle, I very slowly is that neutrons in a small range of kinetie energies are courited for 1.354 sec. Reyister 1 then advances and neutrons in the next small energy range are counted and so on until all neutrons in the range of interest are counted. The small kinetic energy groups can be counted several times.

\section{Comparator Circuit}

The output of the voltage divider is only valid when register 1 and 2 match and when $\mathrm{L}=$ "l". Therefore, a comparator circuit must be designed. The logical expression for 2 bits to match is developed from Table 5.

Table 5. Truth table for matching 2 bits

For One Bit

$\begin{array}{lccl}\underline{A} & \underline{M_{1}} & \underline{M}_{1} \text { (Match) } & \underline{M}_{1}=\bar{A} \bar{F}+A F \\ 0 & 0 & 1 & M_{2}=\bar{B} \bar{G}+B G \\ 0 & 1 & 0 & M_{3}=\bar{C} \bar{H}+C H \\ 1 & 0 & 0 & M_{4}=\bar{D} \bar{J}+D J \\ 1 & 1 & 1 & M_{5}=\bar{E} \bar{K}+E K\end{array}$

The logical expressions in Table 5 are generated one for each 2 bits that are compared, and the 5 logical expressions are "anded" together for a logical 


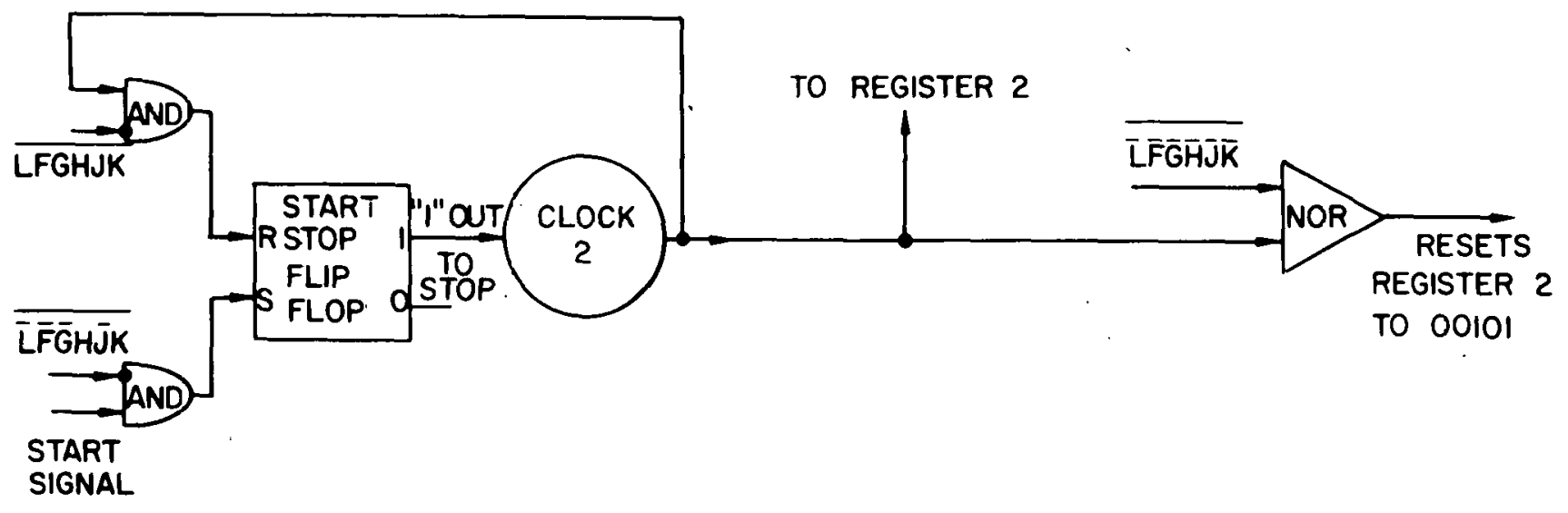

Figure 10. Control for register 2 
expression for the Match (M) of registers 1 and 2. The logical expression $M$ is given below.

$$
M=\left(M_{1}\right)\left(M_{2}\right)\left(M_{3}\right)\left(M_{4}\right)\left(M_{5}\right)
$$

The logical expression for the comparator output (Co) is the "and of $M$ and $L$.

$$
C_{0}=(\bar{A} \bar{F}+A F)(\bar{B} \bar{G}+B G)(\bar{C} \bar{H}+C H)(\bar{D} \bar{J}+D J)(\bar{E} \bar{K}+E K)(L)
$$

Note that an output from the comparator is true only when register 1 and 2 match and $L=" 1 "$ ". The logic diagram for the comparator is shown in Figure 11.

\section{J. Pulse Gate to Analyzer}

The pulse gate shown in Figure 12 performs two functions. First, the voltage from the divider circuit is negative and must be made positive for the analyzer. The gain of -1 is obtained with high gain feedback amplifier. Second, the voltage from the divider circuit is to be gated into the analyzer only when the comparator output is true. This is accomplished with a switching transistor at the input of the amplifier mentioned above.

\section{K. Operation of System}

The complete system now operates in the following manner (Figure 12). Prior to the time that the neutron chopper opens, register 2 is set to 00101 . At $t=0$ clock 2 starts and advances register 2 every $37.5 \mu$ sec. Register 2 will read 00000 after $0.97 \times 10^{-3}$ sec. At this time neutrons in the energy range of interest will be arriving at the detector. The 6th flip-flop (L) driven by register 2 will change to "l" inabling the comparator circuit to fall true if register 1 and register 2 match. When this condition is met, the voltage from the voltage divider circuit is proportional to the kinetic 


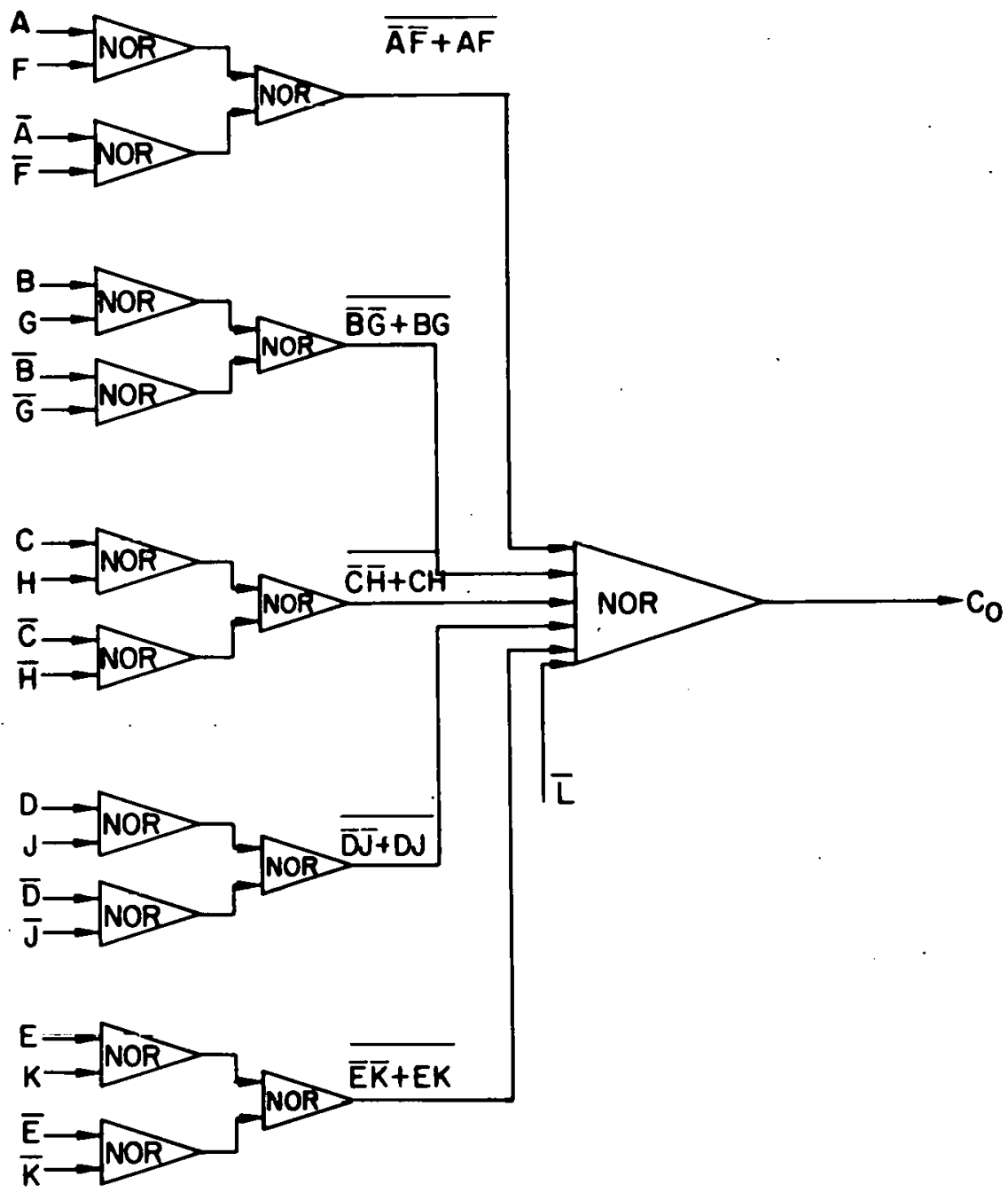

Figure 11. Comparator logic diagram 


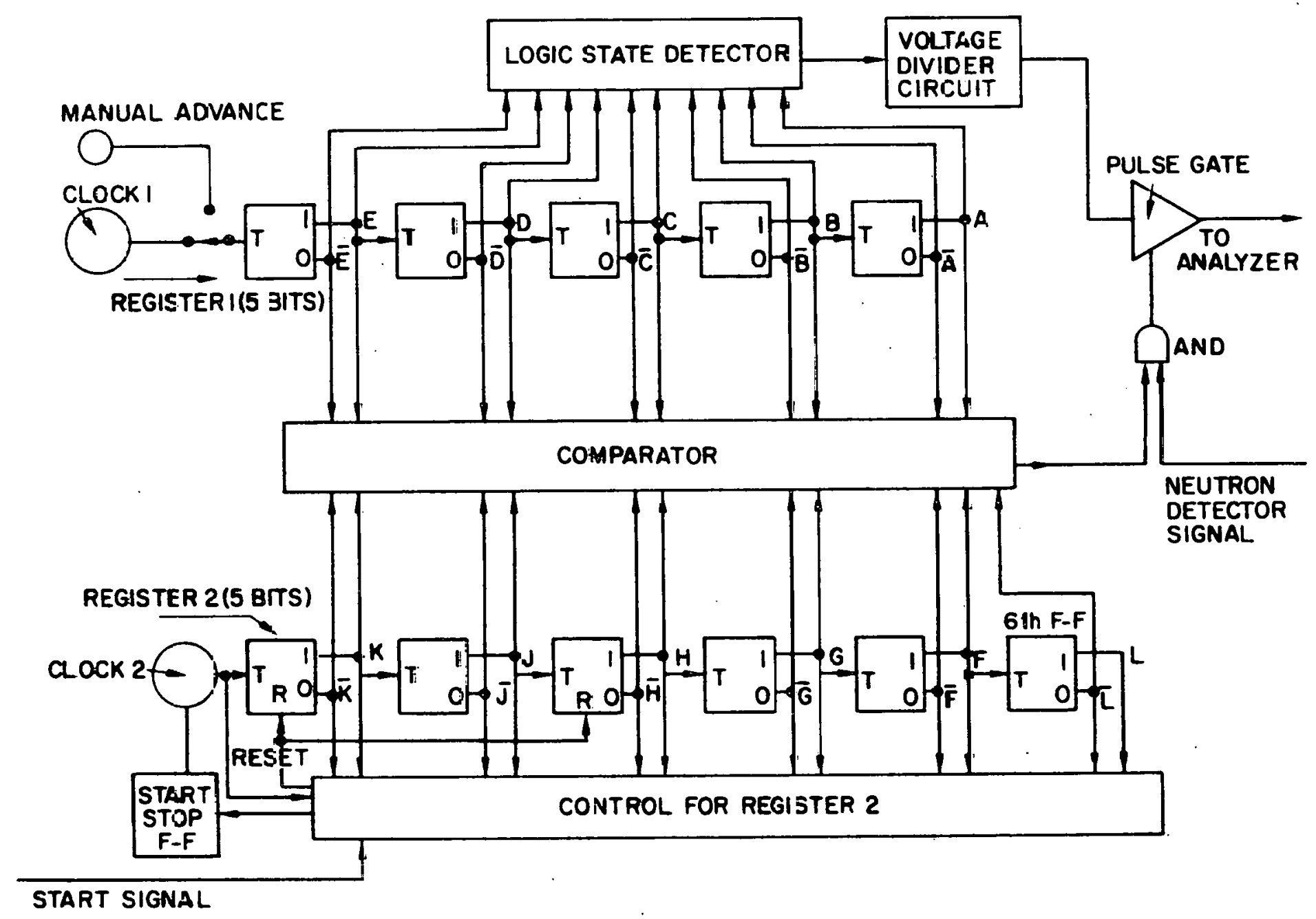

Figure 12. Time of flight to kinetic energy comverter 
energy of the neutrons arriving at the detector. When a neutron strikes the detector, a voltage pulse from detector circuit is "anded" with the comparator circuit. When this is true the pulse gate opens and a voltage pulse from the divider circuit is gated into the analyzer. At $2.17 \times 10^{-3}$ sec. register 2 will be 11111 and $L=1$. On the next clock 2 pulse register 2 and L will advance to 0 . Control for register 2 will stop clock 2 and will set register 2 to 00101 . The preceding operation will occur several times before register 1 advances. As register 1 advances, neutrons arriving at different times $\left(0.97 \times 10^{-3} \mathrm{sec}\right.$. to $\left.2.17 \times 10^{-3} \mathrm{sec}.\right)$ will be counted. 


\section{SYSTEM RESULTS}

\section{A. Pulse Generator Test}

A pulse generator was connected to the start signal input and to the detector input. This generator simulated the start and the end of flight times. The pulse gate was connected to the analyzer. With the pulse generator's period set at $37.5 \mu \mathrm{sec}$. and its output voltage set at +6 volts, register I was allowed to sweep through its 32 states. The analyzer then received the 32 different voltage pulses that the system generates. The count rate for each voltage level was 459 counts/sec. and each level was counted for $1.354 \mathrm{sec}$. Each of the storage channels should have received 622 counts. The voltage levels from the voltage divider circuit are listed in Table 6 with its corresponding storage channel (equation(5)) and the kinetic energy that each storage channel represents (equation (1)). Listed also is the storage channel where the pulses were stored with the number of counts that each storage channel counted. Note from the results that it was not possible to make the system store all the pulses of the same magnleude in one channel. Since they were stored in two channels, the total counts in these two channels must be added together to obtain the correct results. The error introduced by the system storing pulses in a channel close to that for which it was designed is within $+1.9 \%$. This error of the system might he consideled lu bu suro if the corrcct kinetic energy is assigned llie number of pulses stored in each channel. The maximum kinetic energy error ocurrs in the 8 th interval and is the sum $1.9 \%$ error mentioned above and the error in the 8 th interval (2.15\%) due to the stair step approximation. The total error is $4.05 \%$. This error is $.05 \%$ above the $4 \%$ specification. 
Table 6. Results of pulse generator test

\begin{tabular}{|c|c|c|c|c|c|}
\hline & Voltage & $\begin{array}{l}\text { Storage } \\
\text { Channel }\end{array}$ & $\begin{array}{l}\text { Kinetic } \\
\text { Energy }\end{array}$ & $\begin{array}{l}\text { Storage Channel } \\
\text { (Under Test) }\end{array}$ & $\begin{array}{c}\text { Counts } \\
\text { (Under Test) }\end{array}$ \\
\hline $\begin{array}{l}e_{1} \\
e_{2} \\
e_{3} \\
e_{4} \\
e_{5} \\
e_{6} \\
e_{7} \\
e_{8} \\
e_{9} \\
e_{10} \\
e_{11} \\
e_{12} \\
e_{13} \\
e_{14} \\
e_{15} \\
e_{16} \\
e_{17} \\
e_{18} \\
e_{19} \\
e_{20} \\
e_{21} \\
e_{22} \\
e_{23} \\
e_{24} \\
e_{25} \\
e_{26} \\
e_{27} \\
e_{28} \\
e_{29} \\
e_{30} \\
e_{31} \\
e_{32}\end{array}$ & $\begin{array}{l}6.758 \text { volts } \\
6.273 \\
5.838 \\
5.447 \\
5.094 \\
4.774 \\
4.483 \\
4.218 \\
3.976 \\
3.755 \\
3.551 \\
3.363 \\
3.190 \\
3.030 \\
2.882 \\
2.744 \\
2.616 \\
2.497 \\
2.385 \\
2.281 \\
2.184 \\
2.093 \\
2.001 \\
1.926 \\
1.851 \\
1.779 \\
1.712 \\
1.648 \\
1.588 \\
1.531 \\
1.478 \\
1.426\end{array}$ & $\begin{array}{l}337 \\
313 \\
291 \\
272 \\
254 \\
238 \\
224 \\
210 \\
198 \\
187 \\
177 \\
168 \\
159 \\
151 \\
144 \\
137 \\
130 \\
124 \\
1199 \\
114 \\
109 \\
104 \\
100 \\
96 \\
92 \\
88 \\
85 \\
82 \\
79 \\
76 \\
73 \\
71\end{array}$ & $\begin{array}{l}0.0480 \mathrm{ev} . \\
0.0447 \\
0.0416 \\
0.0389 \\
0.0363 \\
0.0340 \\
0.0319 \\
0.0300 \\
0.0283 \\
0.0268 \\
0.0253 \\
0.0240 \\
0.0228 \\
0.0215 \\
0.0206 \\
0.0196 \\
0.0186 \\
0.0177 \\
0.0170 \\
0.0163 \\
0.0156 \\
0.0149 \\
0.0143 \\
0.0137 \\
0.0132 \\
0.0126 \\
0.0122 \\
0.0117 \\
0.0113 \\
0.0108 \\
0.0104 \\
0.0104\end{array}$ & $\begin{array}{r}337,338 \\
315,316 \\
294,295 \\
275,276 \\
257,258 \\
241,242 \\
227,228 \\
213,214 \\
201 \\
188,189 \\
179,180 \\
168,169 \\
160,161 \\
151,152 \\
144,145 \\
137 \\
129,130 \\
124,125 \\
118,119 \\
112,113 \\
108,109 \\
103,104 \\
99,100 \\
95,96 \\
91,92 \\
88,89 \\
84,85 \\
81,82 \\
78,79 \\
75,76 \\
73,74 \\
70,71\end{array}$ & $\begin{array}{l}622 \\
621 \\
621 \\
621 \\
620 \\
621 \\
621 \\
622 \\
622 \\
621 \\
622 \\
622 \\
619 \\
622 \\
619 \\
622 \\
618 \\
621 \\
620 \\
622 \\
619 \\
623 \\
619 \\
619 \\
620 \\
622 \\
621 \\
621 \\
620 \\
622 \\
619 \\
622\end{array}$ \\
\hline
\end{tabular}

The error of the system introduced by the system missing a count can be determined by comparing the counts stored to the counts that should have been received. This error is less than $0.64 \%$.

\section{B. Neutron Spectrum Measurement}

The setup shown in Figure 2 was placed in front of the thermal column at the Ames Laboratory Research Reactor. With the reactor operating at 
5 megawatts, a spectrum was measured for 458 minutes. The results of the spectrum measured are shown in Table 7. Background must be subtracted from the measured number of counts to give the number of neutrons that actually came through the neutron chopper. It was quite difficult to reduce the background relative to the number of neutrons that were coming from the neutron chopper. At the beginning of the run the background was measured to be 258 counts/min. The number of counts to be subtracted from the data because of background is determined by the product of background count rate and the time that each cliaimel cuuld ieceive backyruund counts. Using 258 counts/min. as the background count rate, the background count would be 18. A closer look at the data shows for channels 70-200 that the counts vary from 40 to 55 in a meaningless way. Since very few neutrons were expected in this range, it appears that the background was not 18 but somewhat closer to 50. The background measured at the end of the run showed 180 counts/min., indicating that the background was probably changing with respect to timè. The background subtracted from the counts in Table 7 is 50 . Since the neutron chopper distorts the spectrum received from the reactor, each data point must be corrected. In reference 7 in the section on Discussion of Theory, this conversion factor is discussed. The conversion factor for each kinetic energy is listed in Table 7. The corrected number of counts is obtained by dividing the counts minus background column by the conversion factor. The corrected counts are plotted in Figure 13.

Since the measured spectrum is shifted to the right of the theoretical curve at $20^{\circ} \mathrm{C}$, the indication is that the temperature of the neutrons measured was above $20^{\circ} \mathrm{C}$. The temperature of the neutron with the most probable kinetic energy can be calculated from equation (18-21) on page 575 
Table 7. Measured spectrum

\begin{tabular}{|c|c|c|c|c|}
\hline Channel & Counts & $\begin{array}{c}\text { Counts Minus } \\
\text { Background }\end{array}$ & $\begin{array}{l}\text { Conversion } \\
\text { Factor }\end{array}$ & $\begin{array}{c}\text { Corrected } \\
\text { Counts }\end{array}$ \\
\hline 70,71 & 46 & - & & \\
\hline 73,74 & 48 & - & & \\
\hline 75,76 & 41 & - & & \\
\hline 78,79 & 48 & - & & \\
\hline 81,82 & 54 & - & & \\
\hline 84,85 & 51 & - & & \\
\hline 88,89 & 43 & - & & \\
\hline 91,92 & 47 & - & & \\
\hline 95,96 & 43 & - & & \\
\hline 99,100 & 51. & - & & \\
\hline 103,104 & 42 & - & . & \\
\hline 107,108 & 44 & - & & \\
\hline 112,113 & 47 & - & & \\
\hline 117,118 & 49 & - & & \\
\hline 123,124 & 39 & - & & \\
\hline 129,130 & 38 & - & & \\
\hline 136,137 & 48 & - & & \\
\hline 143,144 & 50 & - & & \\
\hline 159,160 & 44 & - & & \\
\hline 167,168 & 52 & - & & \\
\hline 178,179 & 57 & - & .524 & · \\
\hline 188,189 & .56 & - & .550 & . \\
\hline 199,200 & 50 & - & .575 & \\
\hline 212,213 & 51 & 1 & .600 & 2 \\
\hline 226,227 & 54 & 4 & .623 & 7 \\
\hline 240,241 & 64 & 14 & .647 & 22 \\
\hline 256,257 & 65 & 15 & .669 & 22 \\
\hline 273,274 & 67 & 17 & .691 & 25 \\
\hline 293,294 & 88 & 38 & .711 & 53 \\
\hline 313,314 & 90 & 40 & .731 & 55 \\
\hline 355,336 & 92 & 42 & .750 & 56 \\
\hline
\end{tabular}




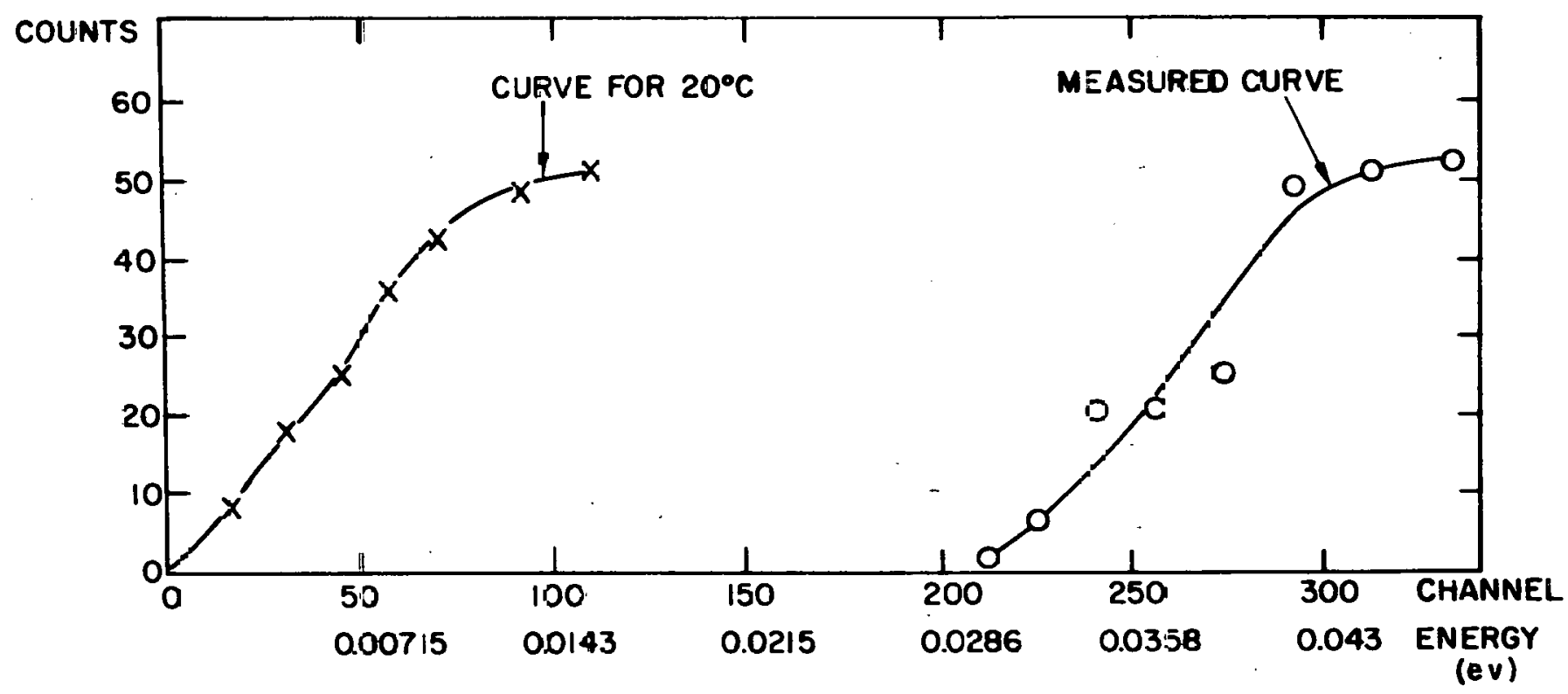

Figure 13. Measured kinetic energy speztrum 
of reference (5). If .05 ev is taken as the most probable energy of the measured spectrum, then the temperature is found to be $307^{\circ} \mathrm{C}$. This temperature is higher than expected. Another source of error, which might be the cause of the curve being shifted too far is the detector distance may have been incorrect. The detector is 12 inches long which makes it difficult to determine the point in the detector that the neutron will be captured. The maximum kinetic energy error due to this 12 inches of uncertainty in 3 meters could be as high as $19 \%$. 
42

VI. DISCUSSION FOR FURTHER STUDY

As far as the system designed is concerned, more accuracy would be desirable. The accuracy of this system could be improved in three ways. First, increasing the number of steps of the voltage divider circuit which would mean increasing the number of states of register 1 . Second, since a pulse height analyzer converts the analog signal received immediately into digital information, a way to transfer the kinetic energy information of register 1 into the analyzer in digital form could be tried. The error introduced by changing register 1 information to analog and then having the analyzer change it back to digital, could be reduced. Third, since the count rate of the neutrons from the chopper was so low, instead of just sampling energies in small ranges, the entire range should be sampled continuously. 


\section{BIBLIOGRAPHY}

1. Averchenkov, V. Y. A. Twenty channel time analyzer for selecting fast neutrons by their time of flight. Instruments and Experimental Techniques 1958: $371-376.1958$.

2. Blinov, M. V. and Kazarinov, N. M. A fission neutron spectrometer. Instruments and Experimental Techniques 1958: 35-40. 1964.

3. Furguson, A. T. C. IBIS a fast neutron time of flight system. Contemporary Physics 5: 270-279. 1964.

4. Hughes, D. J. Pile neutron research. Addison-Wesley Publishing Co., Inc., Cambridge 42, Mass. 1953.

5. Kaplan, Irving. Nuclear Physics. Addison-Wesley Publishing Co., Inc., Reading, Mass. 1963.

6. Lang, T. P. A 64-channel millimicrosecond time analyzer. Institute of Radio Engineers National Convention Record [7], Part 9: 131-140. 1959.

7. Special text for Department of Defense Nuclear Physics. U. S. Atomic Energy Commission Report NP-1910 [Division of Technical Information, AEC]. 1950.

8. Struss, Roland George. The design and operation of a slow neutron chopper. Unpublished M.S. thesis. Library, lowa State University of Science and Technology, Ames, lowa. 1966. 


\section{ACKNOWLEDGMENTS}

I wish to thank Dr. C. J. Triska and Dr. R. C. Camp for their guidance and counseling while 1 was writing this thesis. I also express my thanks to the Ames Laboratory for all the services rendered. 